See discussions, stats, and author profiles for this publication at: https://www.researchgate.net/publication/339330764

\title{
The Role of Halogenative Stress in Atherogenic Modification of Low-Density Lipoproteins
}

Article in Biochemistry (Moscow) - January 2020

DOI: 10.1134/50006297920140035

CITATION

1

4 authors, including:

Irina V Gorudko

Belarusian State University

54 PUBLICATIONS 477 CITATIONS

SEE PROFILE

Some of the authors of this publication are also working on these related projects:

Project $\quad$ Regulation of redox properties in cells View project

Project $\quad$ evaluation of myocardial ischemic-reperfusion injury during on and off-pump coronary artery bypass grafting View project
READS

72

Alexej Victorovich Sokolov

Russian Academy of Medical Sciences

137 PUBLICATIONS 1,230 CITATIONS

SEE PROFILE 


\title{
The Role of Halogenative Stress in Atherogenic Modification of Low-Density Lipoproteins
}

\author{
O. M. Panasenko ${ }^{1, a *}$, T. I. Torkhovskaya ${ }^{1,2}$, I. V. Gorudko ${ }^{3}$, and A. V. Sokolov ${ }^{1,4, b}$ \\ ${ }^{1}$ Federal Research and Clinical Center of Physico-Chemical Medicine, \\ Federal Medical Biological Agency, 119435 Moscow, Russia \\ ${ }^{2}$ Orekhovich Institute of Biomedical Chemistry, 119121 Moscow, Russia \\ ${ }^{3}$ Belarusian State University, 220030 Minsk, Belarus \\ ${ }^{4}$ Institute of Experimental Medicine, 197376 St. Petersburg, Russia \\ ae-mail: o-panas@mail.ru \\ ${ }^{b} e$-mail: biochemsokolov@gmail.com
}

Received March 26, 2019

Revised April 15, 2019

Accepted April 18, 2019

\begin{abstract}
This review discusses formation of reactive halogen species (RHS) catalyzed by myeloperoxidase (MPO), an enzyme mostly present in leukocytes. An imbalance between the RHS production and body's ability to remove or neutralize them leads to the development of halogenative stress. RHS reactions with proteins, lipids, carbohydrates, and antioxidants in the content of low-density lipoproteins (LDLs) of the human blood are described. MPO binds site-specifically to the LDL surface and modifies LDL properties and structural organization, which leads to the LDL conversion into proatherogenic forms captured by monocytes/macrophages, which causes accumulation of cholesterol and its esters in these cells and their transformation into foam cells, the basis of atherosclerotic plaques. The review describes the biomarkers of MPO enzymatic activity and halogenative stress, as well as the involvement of the latter in the development of atherosclerosis.
\end{abstract}

DOI: $10.1134 / \mathrm{S} 0006297920140035$

Keywords: myeloperoxidase, reactive halogen species, halogenative stress, low-density lipoproteins, modification of lowdensity lipoproteins, biomarkers of halogenative stress, atherosclerosis

The main transport form of cholesterol and cholesterol esters in human blood is low-density lipoproteins (LDLs). Increased cholesterol and LDL concentration in the plasma is a diagnostic criterion for the risk of atherosclerosis [1]. Atherosclerosis is a chronic vascular disease associated with the development of atheromatous plaques due to progressive accumulation of cholesterol. The resulting narrowing of the vessels lumen leads to the development of cardiovascular diseases (CVDs). In the light of classic works of N. N. Anichkov, the founder of

Abbreviations: ApoB100, apolipoprotein B-100; CP, ceruloplasmin; CVD, cardiovascular disease; HDL, high-density lipoprotein; LDL, low-density lipoprotein; LDL-Br, low-density lipoprotein modified by $\mathrm{HOBr}$; LDL-Cl, low-density lipoprotein modified by $\mathrm{HOCl}$; LPO, lipid peroxidation; mLDL, modified low-density lipoprotein; MPO, myeloperoxidase; RHS, reactive halogen species; VLDL, very low-density lipoprotein.

* To whom correspondence should be addressed. the "cholesterol theory" of atherosclerosis, who postulated that "there is no atherosclerosis without cholesterol" [2], the main efforts in atherosclerosis therapy and prevention have been directed at normalizing the concentration of total cholesterol in the plasma. In 1960s, J. W. Gofman used analytical ultracentrifugation for isolating cholesterol-transporting lipoproteins from the blood plasma [3, 4], and found an increase in the LDL concentration in heart attack patients. By the end of 1970s, it had been proven that LDLs are the source of lipids accumulating in the blood vessels. Hypercholesterolemia associated with a high content of LDLs is still considered the most serious risk factor in CVDs [5].

First studies aimed on the characterization of physicochemical properties of lipoproteins (and not only at determination of their individual classes quantities) appeared in 1970s-1980s. Later, the concept of modified LDLs (mLDLs) different from the LDLs in the plasma of healthy individuals with a known content and ratio of 


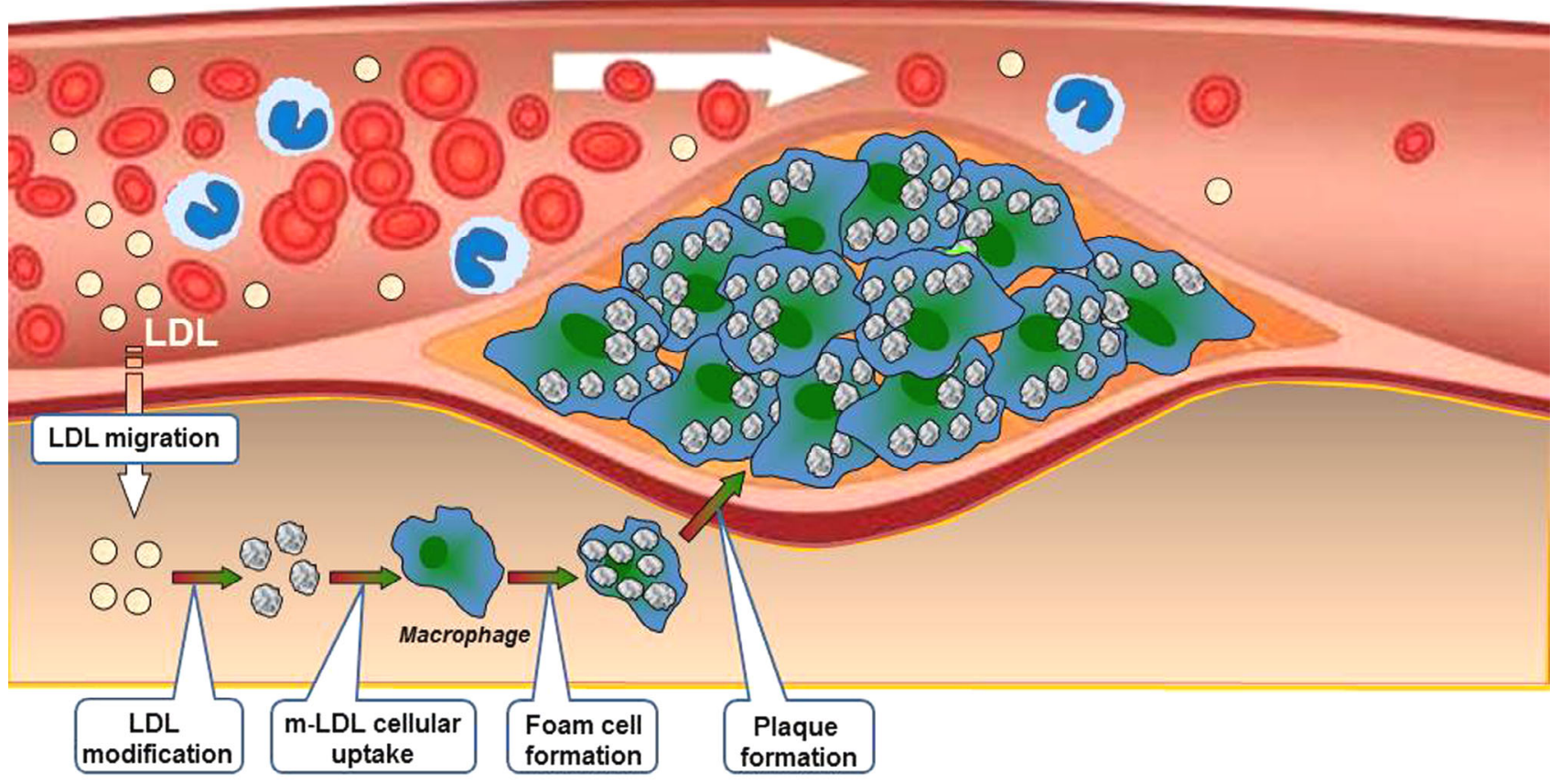

Fig. 1. The role of mLDLs in the formation of atherosclerotic plaques and atherosclerosis development (see the text). (Colored versions of Figs. 1 and 7 are available in electronic version of the article on the site http://sciencejournals.ru/journal/biokhsm/)

protein and lipid components, was generated [6, 7]. Vascular cells and many blood cells capture native LDLs through special ApoB and ApoE receptors. This physiological mechanism of lipid reserve replenishment by the cells is regulated by the negative feedback mechanism and prevents cell overloading with cholesterol [8]. Modifications of the LDL surface result in the generation of mLDLs unrecognized by the ApoB and ApoE receptors. However, mLDLs can be captured by the unregulated scavenger receptor on macrophages and vascular smooth muscle cells. Cell oversaturation with cholesterol esters results in its transformation into the foam cell that serves as a basis of future atherosclerotic plaque [9, 10]. These finding gave rise to a new concept on the leading role of mLDLs in atherogenesis associated with various types of atherogenic LDL modifications. Transformation into foam cells via activity of scavenger receptors takes place regardless of the mechanism of LDL modification: oxidation [11, 12], proteolysis [13, 14], lipolysis [15], desialylation [16, 17], or glycosylation [18].

The role of mLDLs in atherogenesis (in a simplified scheme) is shown in Fig. 1. LDLs migrate from the bloodstream to the subendothelial space, where they become potential targets for various enzymatic and nonenzymatic modifications. The capture of the generated mLDLs by scavenger receptors leads to the overload of phagocytes with cholesterol. Transformation of phagocytes into foam cells initiates formation of atherosclerotic plaques.
The blood of CVD patients contains proatherogenic LDL subfractions that differ from native LDLs in their physicochemical properties. These subfraction include oxidized, electronegative, desialylated, small dense, or aggregated LDLs [19-21]. The main reason for the proatherogenic modification of LDLs has not yet been elucidated. It was suggested that the essential role of atherogenic LDL modifier belong to myeloperoxidase (MPO), based on the elevated levels of this enzyme in atherosclerotic areas of the aorta [22] and in the blood plasma of CVD patients [23]. MPO is expressed by neutrophils and monocytes and secreted into the extracellular space upon their activation to provide the antimicrobial defense [24]. MPO catalyzes oxidation of halogen ions to the corresponding hypohalous acids. Hypochlorous acid ( $\mathrm{HOCl})$ is the most important natural precursor of free radicals produced as result of chloride oxidation by MPO [25]. At the same time, $\mathrm{HOCl}$ and other hypohalous acids trigger the formation of active halogen-containing compounds interacting with protein and lipids in LDLs. These compounds have been named in recent years as reactive halogen species (RHS) [25, 26] by analogy with widely used terms reactive oxygen species and reactive nitrogen species $[27,28]$.

This review summarizes the data on the effects of MPO, RHS, and halogenative stress (response induced by these compounds) on LDL properties increasing their atherogenicity and responsible for the formation of atherosclerotic lesion in the vascular wall. 


\section{ENZYMATIC ACTIVITIES OF MYELOPEROXIDASE. REACTIVE HALOGEN SPECIES. HALOGENATIVE STRESS}

Mature MPO is a glycosylated homodimer $\left(M_{\mathrm{w}} \sim\right.$ $145 \mathrm{kDa}$ ) consisting of two light $\beta$-subunits and two heavy $\alpha$-subunits containing heme and cysteine residues involved in the formation of disulfide bond between the subunits [29]. The enzyme is found mainly in azurophilic granules of neutrophils and in lysosomes of monocytes. The content of MPO in neutrophils is estimated as 2-5\% of total cell protein or $2-4 \mu \mathrm{g}$ per $10^{6}$ cells. The content of MPO in monocytes is $\sim 0.9 \%$ of cell weight [30-32]. Degranulation of neutrophils and monocytes during their activation results in the MPO release into the extracellular space $(>20 \%$ of the MPO total content in neutrophils [33]). MPO can appear outside of neutrophils as a result of necrosis or NETosis [34]. MPO itself is a strong autocrine regulator of neutrophil function. It activates tyrosine kinases by binding to the CD11b/CD18 integrin on the surface of neutrophils and increases cytosolic $\mathrm{Ca}^{2+}$ concentration, which ultimately promotes degranulation and contributes to further release of granule proteins (including MPO) to the extracellular space [35-38].

Figure 2 shows major MPO-catalyzed reactions. At the first stage (reaction 1), the native enzyme reacts with the $\mathrm{H}_{2} \mathrm{O}_{2}$ forming the so-called Compound I. The latter has two oxidative equivalents and, similarly to any peroxidase, performs sequential single-electron oxidation of various substrates (nitrite, ascorbate, tyrosine, etc.) through the formation of Compound II followed by return to the native enzyme form and completion of the peroxidase

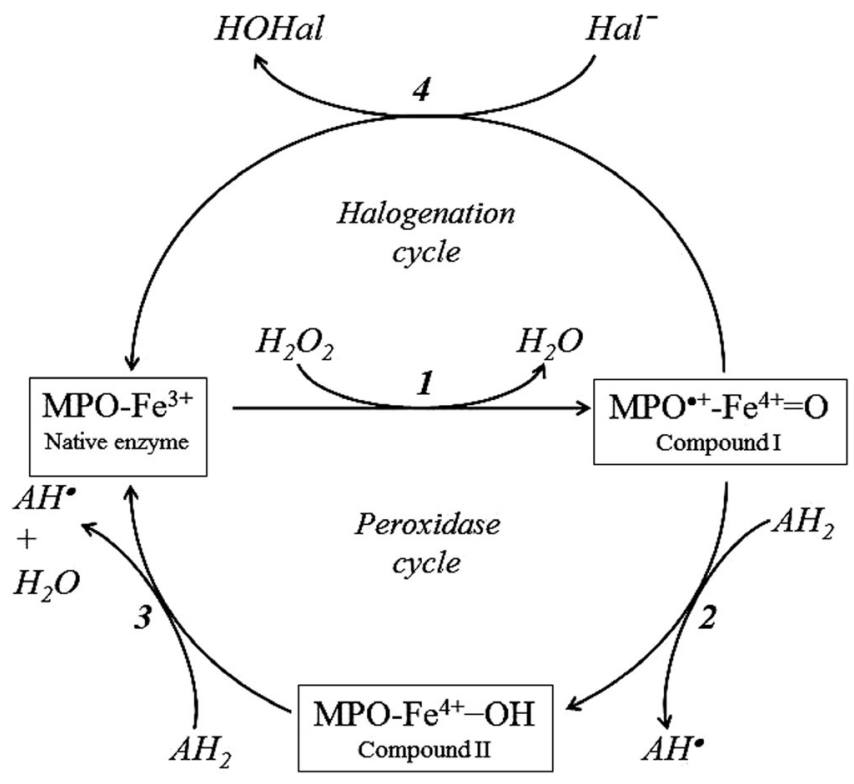

Fig. 2. Halogenation and peroxidase cycles of MPO. Hal, halogen; $\mathrm{AH}_{2}$, peroxidase substrate. cycle (reactions 1-3). Unlike conventional peroxidases, Compound I MPO is also capable of immediate two-electron oxidation of halides (reaction 4), such as chloride $\left(\mathrm{Cl}^{-}\right)$, bromide $\left(\mathrm{Br}^{-}\right)$or iodide $\left(\mathrm{I}^{-}\right)$, with the formation of hypochlorous $(\mathrm{HOCl})$, hypobromous $(\mathrm{HOBr})$, or hypoiodous (HOI) acids, respectively, and completion of the halogenation cycle (reactions 1 and 4) [25]:

$$
\mathrm{H}_{2} \mathrm{O}_{2}+\mathrm{Hal}^{-}+\mathrm{H}^{+} \rightarrow \mathrm{HOHal}+\mathrm{H}_{2} \mathrm{O},
$$

where $\mathrm{Hal}$ is a halogen atom. $\mathrm{HOCl}$ salts are called hypochlorites. The molecular form of $\mathrm{HOCl}$ and the dissociated hypochlorite anion are present in approximately equal concentrations, because $\mathrm{p} K_{\mathrm{a}} \mathrm{HOCl}$ is $\sim 7.5$ [39] in aqueous medium at physiological $\mathrm{pH}$ values:

$$
\mathrm{HOCl} \leftrightarrows \mathrm{OCl}^{-}+\mathrm{H}^{+}
$$

Bromide $(20-100 \mu \mathrm{M})$ and iodide $(<0.6 \mu \mathrm{M})$ that are present in the blood plasma in significantly lower concentrations than chloride, are also oxidized by MPO [40]. Halogen-containing reactive compounds formed by the enzymatic activity of MPO (first of all, hypohalous acids) are commonly called primary RHS [25, 26].

Due to the high reactivity, primary RHS interact with many functional groups of various compounds, leading to the formation of secondary RHS. The products of hypohalous acid interaction with amines and amides are the most important secondary RHS that damage the protein and lipid components of LDLs. The reaction of primary amines with $\mathrm{HOCl}$ and $\mathrm{HOBr}$ produces mono- and dichloramines and mono- and dibromamines, respectively $\left(\mathrm{R}-\mathrm{NHCl}, \mathrm{R}-\mathrm{NCl}_{2}, \mathrm{R}-\mathrm{NHBr}\right.$, and $\mathrm{R}-\mathrm{NBr}_{2}$, where $\mathrm{R}$ is any molecule containing an amino group) [25, 41]. Low concentrations of $\mathrm{HOCl}$ and, especially $\mathrm{HOBr}$, lead to the predominant formation of monohalogenamines under physiological conditions [25]. It is important to note that all major classes of biomolecules in the content of LDLs (proteins, phospholipids, carbohydrates) contain primary amino groups. A similar reaction of amides $\left(\mathrm{R}-\mathrm{C}(\mathrm{O})-\mathrm{NHR}_{1}\right.$ ) with $\mathrm{HOCl}$ or $\mathrm{HOBr}$ leads to the formation of chloro- and bromamides $\left(\mathrm{R}-\mathrm{C}(\mathrm{O})-\mathrm{NClR}_{1}\right.$ and $\left.\mathrm{R}-\mathrm{C}(\mathrm{O})-\mathrm{NBrR}_{1}\right)$, respectively [25, 41]. Secondary RHS also react with functional groups of proteins and other biomolecules, although at a slower rate than primary, most often by replacing the hydrogen atom with the halogen atom $[25,41]$.

Secondary RHS are also formed in the reactions of hypohalous acids with inorganic compounds. For example, $\mathrm{HOCl}$ oxidizes nitrite to nitrate in the following reaction $\left(k=7.4 \cdot 10^{3} \mathrm{M}^{-1} \cdot \mathrm{s}^{-1}\right.$ at $\mathrm{pH} 7.2$ and $\left.25^{\circ} \mathrm{C}\right)$ [42]:

$$
\mathrm{HOCl}+\mathrm{NO}_{2}^{-} \rightarrow \mathrm{Cl}^{-}+\mathrm{H}^{+}+\mathrm{NO}_{3}^{-} .
$$

Nitrile chloride $\left(\mathrm{NO}_{2} \mathrm{Cl}\right)$ is formed as an intermediate in this reaction [43]. Phenolic compounds, in particular

BIOCHEMISTRY (Moscow) Vol. 85 Suppl. 12020 
tyrosine, are efficiently nitrated and, especially, chlorinated by $\mathrm{NO}_{2} \mathrm{Cl}$ [42]. The latter decomposes into radicals [43]:

$$
\mathrm{NO}_{2} \mathrm{Cl} \rightarrow{ }^{\cdot} \mathrm{NO}_{2}+\mathrm{Cl}^{\cdot}
$$

leading to tyrosyl radical formation [43] and lipid peroxidation (LPO) in LDLs [42, 44].

It should be emphasized that unlike reactive oxygen species $\left(\mathrm{H}_{2} \mathrm{O}_{2},{ }^{\cdot} \mathrm{O}_{2}^{-},{ }^{\circ} \mathrm{OH}\right.$, etc. $)$, the oxidative capacity of RHS is determined by the halogen atom and not by the oxygen atom. It is the halogen atom that participates in the redox reaction by accepting electrons from the oxidized compound and turning into halide:

$$
\mathrm{HOHal}+2 \mathrm{e}+\mathrm{H}^{+} \rightarrow \mathrm{Hal}^{-}+\mathrm{H}_{2} \mathrm{O}
$$

Due to this, hypohalous acids are strong two-electron oxidizing agents with the oxidizing ability decreasing in order: $\mathrm{HOCl}>\mathrm{HOBr}>\mathrm{HOI}$ (redox potentials for the $\mathrm{HOHal} / \mathrm{Hal}^{-}, \mathrm{H}_{2} \mathrm{O}$ pairs are $1.08,0.93$, and $0.57 \mathrm{~V}$, respectively) [45].

It is clear that attributing RHS to reactive oxygen species, as it has been done by some authors [46, 47], is fundamentally erroneous. Other names used in the literature, such as chlorinating/brominating oxidants [48], chlorinating intermediates [49], and reactive chlorinating/brominating species [50, 51], do not reflect the board reactivity of the halogen atom manifested in oxidative and other reactions (substitution, addition, etc.) [25, 26, 41]. In our opinion, the term reactive halogen species (RHS) proposed in our earlier works $[25,26,52]$ and used by other authors [53,54], is more informative and correct.

The pronounced antimicrobial activity of RHS used in nature for the rapid destruction of infectious pathogens in the inflammation foci is also potentially dangerous, since an uncontrolled efflux of RHS can damage biomolecules and supramolecular structures [25]. This does not occur in a healthy organism, where excessive production of RHS is controlled by a number of factors preventing MPO release by neutrophils, suppression of MPO activity, and RHS scavenging. However, depletion of the anti-halogenative system with simultaneous increase in the RHS production can provoke a so-called halogenative stress characterized by the imbalance between the RHS formation and organism's ability to remove or to neutralize them [25, 26]. Apparently, halogenative stress cannot exist by itself. It is closely associated with the oxidative, nitrosative, and carbonyl stresses, since RHS reactions with various compounds and functional groups leads to the formation of reactive oxygen and nitrogen species and carbonyl compounds [26].

\section{RHS INTERACTION WITH LDL COMPONENTS}

Based on the kinetic models and experimental data, it was found that the main targets of $\mathrm{HOCl}$ and $\mathrm{HOBr}$ in
LDLs are Met, Cys, His, Trp, Lys, and Tyr residues, disulfide bonds and terminal primary amino groups of proteins, polar heads of phosphatidylethanolamine and phosphatidylserine, cholesterol unsaturated bonds, and antioxidants (carotenoids, tocopherol, and ubiquinol). Arginine residues and unsaturated bonds of aliphatic fatty acid chains of phospholipids react with $\mathrm{HOBr}$ faster than with $\mathrm{HOCl}$. The rate constants of the secondorder reactions of $\mathrm{HOCl}$ and $\mathrm{HOBr}$ with the functional groups of these compounds are shown in the table; as a rule, they range from $10^{3}$ to $10^{8} \mathrm{M}^{-1} \cdot \mathrm{s}^{-1}$. Primary RHS react with Gln and Asn residues and protein peptide bonds at a much lower rate and virtually do not react with Ala, Val, Leu, Ile, Pro, and Phe and phosphocholine group of phosphatidylcholine [55-59]. Below, we will discuss in detail the RHS-induced changes in the LDL components (proteins, lipids, carbohydrates, antioxidants) that can be the cause of LDL proatherogenic modification.

Modification of ApoB100. ApoB100 $\left(M_{\mathrm{w}} \sim 512 \mathrm{kDa}\right)$ is the main protein component of LDLs (up to 98\%) recognized by the ApoB and ApoE receptors on the cell surface. Incubation of LDLs in the presence of various $\mathrm{HOCl}$ concentrations leads to the decrease in the content of amino acid residues in the following order: Met $\sim$ Cys $>$ Lys $\sim$ Tyr $>$ His $\sim$ Arg [57]. A number of studies have compared the loss of ApoB100 functional groups in LDLs under the action of $\mathrm{HOCl}$ and in the presence of MPO + $\mathrm{H}_{2} \mathrm{O}_{2}+\mathrm{Cl}^{-}$. Most of these studies have confirmed similar effects of $\mathrm{HOCl}$ and $\mathrm{MPO}+\mathrm{H}_{2} \mathrm{O}_{2}+\mathrm{Cl}^{-}$, thereby proving the key role of MPO-generated $\mathrm{HOCl}$ as the modifying agent $[60,61]$.

However, in some cases, ApoB100 modifications were different after MPO binding to the LDL surface and $\mathrm{HOCl}$ addition $[62,63]$. The effects of $\mathrm{HOCl}$ and functioning MPO (MPO $+\mathrm{H}_{2} \mathrm{O}_{2}+\mathrm{Cl}^{-}$) on the modification of amino acid residues in LDL were investigated in [63]. The authors identified 97 peptides containing modified residues (mostly Met, Trp, and Tyr) after trypsinolysis of ApoB100 and found significant differences between peptides modified by $\mathrm{HOCl}$ and MPO. It was suggested that this difference was due to the site-specific modification of ApoB100 after MPO binding to the LDL surface (in contrast to the LDL modification by $\mathrm{HOCl}$ ) or by a considerable increase (up to 90\%) in the MPO activity upon enzyme binding to the LDL. Analysis of peptides obtained by trypsinolysis of ApoB100 in the content of LDLs isolated from the blood of patients with a high risk of CVD revealed a certain similarity between peptides modified in vitro and in vivo. Interestingly, some residues (Met4, Met785, Met1873, Met2015, Trp2468, Trp3943, and Met4192) were already modified in the native LDLs, which indicates their hypersensitivity to RHS [63].

According to the kinetics of modification of ApoB100 amino acid residues, $\mathrm{HOBr}$ is generally more active than $\mathrm{HOCl}$. HOBr reacts with His, Trp, Lys, Tyr, 
The content of functional groups in ApoB100, lipids, and antioxidants in LDLs and the rate constants of the secondorder reactions of these groups with $\mathrm{HOCl}$ and $\mathrm{HOBr}$

\begin{tabular}{l|c|c|c}
\hline \multicolumn{1}{c|}{ LDL component } & Number of molecules per LDL particle & $k_{\mathrm{HOCl}}, \mathrm{M}^{-1} \cdot \mathrm{s}^{-1}$ & $k_{\mathrm{HOBr}}, \mathrm{M}^{-1} \cdot \mathrm{s}^{-1}$ \\
\hline ApoB100 & {$[58]$} & {$[55]$} & {$[56]$} \\
Met & 78 & $3.8 \cdot 10^{7}$ & $3.6 \cdot 10^{6}$ \\
Cys & 9 & $3.0 \cdot 10^{7}$ & $1.2 \cdot 10^{7}$ \\
Disulfide bond & 8 & $1.6 \cdot 10^{5}$ & $1.1 \cdot 10^{6}$ \\
His & 115 & $1.0 \cdot 10^{5}$ & $3.0 \cdot 10^{6}$ \\
Lys & 357 & $5.0 \cdot 10^{3}$ & $2.9 \cdot 10^{5}$ \\
Trp & 37 & $1.1 \cdot 10^{4}$ & $3.7 \cdot 10^{6}$ \\
Tyr & 151 & 44 & $2.3 \cdot 10^{5}$ \\
Arg & 148 & 26 & $1.8 \cdot 10^{3}$ \\
Asn & 247 & 0.03 & 1.9 \\
Gln & 230 & 0.03 & 1.9 \\
Terminal NH ${ }_{2}$-group & 1 & $1.0 \cdot 10^{5}$ & $2.0 \cdot 10^{6}$ \\
Peptide bond & 4535 & 10 & $50-900$ \\
& & & {$[59]$} \\
Lipids & {$[58]$} & {$[58]$} & $9.3 \cdot 10^{5}$ \\
Phosphatidylserine* & 5 & $3.3 \cdot 10^{4}$ & $8.8 \cdot 10^{5}$ \\
Phosphatidylethanolamine* & 15 & $1.8 \cdot 10^{4}$ & - \\
Phosphatidylcholine* & 610 & 0.018 & $1.1 \cdot 10^{4}$ \\
Double bonds & 5095 & 8.7 & - \\
Sphingomyelin (amide) & 171 & $18.7[93]$ & {$[59]$} \\
& & & $6.4 \cdot 10^{4}$ \\
Antioxidants & {$[144]$} & $1.3 \cdot 10^{3}[58]$ & $2.5 \cdot 10^{6}$ \\
Tocopherol & 7 & $1.3 \cdot 10^{3}[58]$ & - \\
Ubiquinol & 0.10 & $2.3 \cdot 10^{4}[146]$ & \\
$\beta$-Carotene & 0.29 & & \\
& & & \\
\hline
\end{tabular}

* Rate constant for the reaction with the phospholipid polar heads.

Arg, terminal $\mathrm{NH}_{2}$-groups, and disulfide bonds faster than $\mathrm{HOCl}[55,56]$.

Interaction between primary RHS and proteins often leads to protein aggregation due to the formation of intermolecular cross-links. There are three mechanisms for the formation of such crosslinks associated with the MPO activity.

The first mechanism is $\mathrm{HOCl}(\mathrm{HOBr})$ reaction with $\mathrm{NH}_{2}$-groups with the formation of aldehyde that can proceed by two independent ways. The first one is the formation of unstable chlor- and bromamines in the reaction with the terminal $\alpha-\mathrm{NH}_{2}$ group with their following conversion into aldehydes through decarboxylation and deamination:

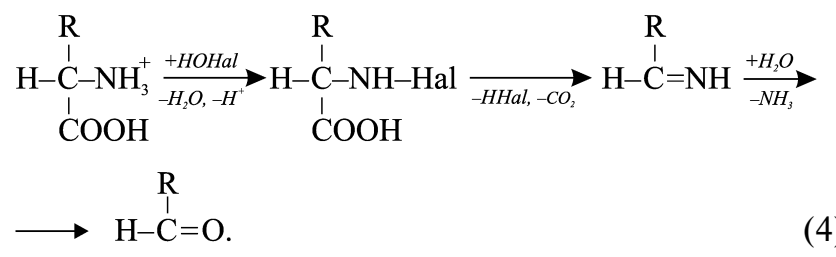

The second one is formation of more stable chlorand bromamines formed in the reaction of $\mathrm{HOCl}$ and
$\mathrm{HOBr}$ with the $\mathrm{NH}_{2}$-groups of Lys side chains with the following homolytic decomposition of the $\mathrm{N}-\mathrm{Hal}$ bond:

$$
\mathrm{R}-\mathrm{CH}_{2}-\mathrm{HN}-\mathrm{Hal} \rightarrow \mathrm{R}-\mathrm{CH}_{2}-\mathrm{HN}{ }^{\bullet}+{ }^{\cdot} \mathrm{Hal} .
$$

Under aerobic conditions, the $\mathrm{N}$-centered radical migrates to the next $\mathrm{C}$-atom with the aldehyde formation [64]:

$$
\begin{aligned}
& \mathrm{R}-\mathrm{CH}_{2}-\dot{\mathrm{N}} \mathrm{H} \longrightarrow \mathrm{R}-\dot{\mathrm{C}} \mathrm{H}-\mathrm{NH}_{2} \stackrel{+\mathrm{O}_{2}}{\longrightarrow} \stackrel{\stackrel{\mathrm{OO}}{\longrightarrow}}{\stackrel{\mathrm{I}}{\mathrm{C}} \mathrm{C}-\mathrm{NH}_{2} \underset{-\mathrm{HO}_{2}^{\circ}}{\longrightarrow}} \\
& \mathrm{R}-\mathrm{CH}=\mathrm{NH} \underset{-\mathrm{NH}_{3}}{\stackrel{+\mathrm{H}_{2} \mathrm{O}}{\longrightarrow}} \mathrm{R}-\mathrm{CH}=\mathrm{O} \text {. }
\end{aligned}
$$

Aldehyde reaction with the $\mathrm{NH}_{2}$-group (mainly of Lys) results in the formation of both intra- and intermolecular cross-links:

$$
\mathrm{R}-\mathrm{CH}=\mathrm{O}+\mathrm{R}_{1}-\mathrm{CH}_{2}-\mathrm{NH}_{2} \underset{-H_{2} \mathrm{O}}{\longrightarrow} \mathrm{R}-\mathrm{CH}=\mathrm{N}-\mathrm{CH}_{2}-\mathrm{R}_{1} \text {. }
$$

The mechanism of the formation of intermolecular crosslinks is the interaction between $\mathrm{HOCl}$ and the $\mathrm{SH}$ group of Cys residue according to the scheme: 


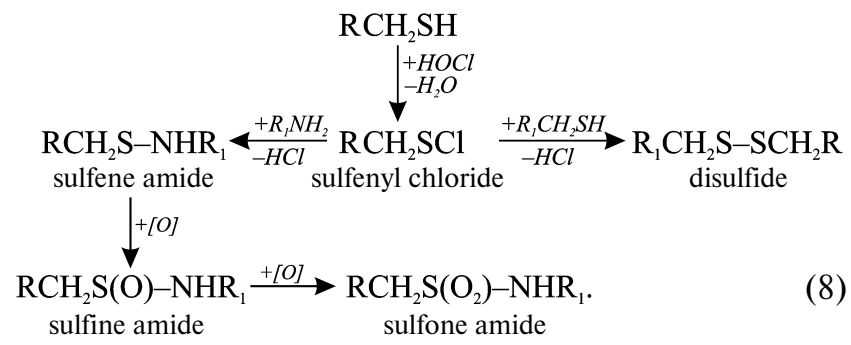

The resulting unstable sulfenyl chloride reacts with the $\mathrm{SH}$-group of Cys with the formation of disulfide bond $(-\mathrm{S}-\mathrm{S}-)$ or with the amino group of Lys with the formation of sulfene amide ( $-\mathrm{NH}-\mathrm{S}-$ covalent crosslinking). The latter undergoes further oxidation to sulfine amide and then to sulfone amide $[65,66]$.

Finally, the third mechanism of the cross-link formation in protein is MPO-dependent but not associated with the RHS formation. Tyrosyl radical formed by the one-electron oxidation of Tyr residue in the MPO peroxidase cycle dimerizes into di-Tyr, resulting to the crosslinking [67].

Protein interaction with primary RHS can result in the destruction of peptide bonds and protein fragmentation. Interaction of peptide bond amide group with $\mathrm{HOCl}$ or $\mathrm{HOBr}$ can lead to the replacement of the hydrogen atom by the halogen atom with the formation of chlor- or bromamides, respectively $[25,55,56]$. The rate constants of the bimolecular reactions of $\mathrm{HOCl}$ and $\mathrm{HOBr}$ with compounds mimicking the peptide bond strongly depend on the compound chemical structure and vary within 3-4 orders of magnitude. Moreover, the rate of amide group reaction with $\mathrm{HOBr}$ is about 30-40 times higher than with $\mathrm{HOCl}[55,56]$. In aqueous medium, chloramides are slowly hydrolyzed, resulting in peptide bond cleavage and protein fragmentation [68]. Using the spin trap method, it was shown that the $\mathrm{N}-\mathrm{Cl}(\mathrm{Br})$ bond can undergo homolytic cleavage with the formation of an $\mathrm{N}$-centered radical, e.g., in the presence of ions of transition metals. The $\mathrm{N}$-centered radical is transformed via intramolecular rearrangement into the $\mathrm{C}$-centered radical, leading to the polypeptide chain fragmentation [64, 69]. However, some authors believe that due to the fact that the rate constant for the $\mathrm{HOCl}$ reaction with the amide bond does not exceed $25 \mathrm{M}^{-1} \cdot \mathrm{s}^{-1}$ [55], its occurrence in the LDL in vivo is unlikely [57].

ApoB100 can be also modified by nitrile chloride $\left(\mathrm{NO}_{2} \mathrm{Cl}\right)$. Nitrile chloride is formed as an intermediate in the nitrite reaction with $\mathrm{HOCl}$ and decomposes into free radicals (reaction 3). It was found that Tyr residues are chlorinated and nitrated by $\mathrm{NO}_{2} \mathrm{Cl}$ with the formation of tyrosyl radical [42-44]. Nitrated ApoB100 in LDL particles is selectively recognized by the CD36 scavenger receptor on the vascular cells [70]. Similar process can take place in the inflammation foci characterized by increased concentrations of both nitrite and $\mathrm{HOCl}[57]$.
Modification of lipids. The major targets of RHS in the LDL lipids are unsaturated $-\mathrm{CH}=\mathrm{CH}-$ bonds of fatty acids and cholesterol and $\mathrm{NH}_{2}$-groups of polar heads of some phospholipids.

$R H S$ reactions with unsaturated bonds. There are two main mechanisms of RHS reactions with unsaturated $-\mathrm{CH}=\mathrm{CH}-$ bonds: molecular mechanism occurring without participation of free radicals and free-radical mechanism (LPO) proceeding through the formation of peroxides and radical intermediate.

The molecular mechanism involves electrophilic addition of $\mathrm{HOCl}$ or $\mathrm{HOBr}$ to the double bond according to the reaction (9) with the formation of chloro- or bromohydrin isomers, respectively [71-73].

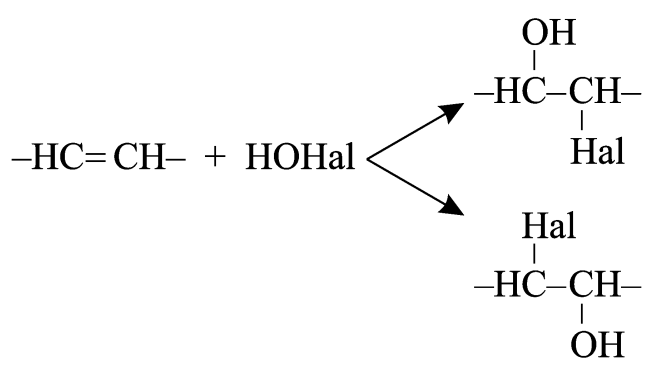

The same products are formed when unsaturated phospholipids are incubated even in the presence of $\mathrm{MPO}+\mathrm{H}_{2} \mathrm{O}_{2}+$ halide. Formation of chloro- or bromohydrin is completely prevented by the absence of MPO or one of the substrates $\left(\mathrm{H}_{2} \mathrm{O}_{2}\right.$ or halide) in the incubation medium or by addition of sodium azide (MPO inhibitor), taurine, or Met (scavenger of $\mathrm{HOCl}$ and $\mathrm{HOBr}$ ) to the reaction. This proves that $\mathrm{HOCl}$ and $\mathrm{HOBr}$ formed in the MPO-catalyzed reaction participate in the synthesis of chloro- and bromohydrins, respectively [74-81].

If a fatty acid chain contains several unsaturated bonds, any of them can be attacked by $\mathrm{HOCl}$ (or $\mathrm{HOBr}$ ). In the presence of excessive amounts of hypohalous acids, all double bonds enter the reaction [72, 73, 82]. Interaction of polyunsaturated phospholipids containing arachidonic or docosahexaenoic acids with hypohalous acids or $\mathrm{MPO}+\mathrm{H}_{2} \mathrm{O}_{2}+\mathrm{Cl}^{-} / \mathrm{Br}^{-}$results in the formation of lysophospholipids as main reaction products. This is related to the negative inductive effect ( $-I$ effect) caused by the introduction into acyl chains of electron acceptor substituents, such as $\mathrm{Cl}, \mathrm{Br}, \mathrm{OH}$, during the synthesis (reaction 9) of chloro- or bromohydrins. The $-I$ effect leads to the hydrolysis of ester bond due to the formation of the electron density deficit on the ester bond carbon atom [77, 79-83].

No formation of lysophospholipids in the reaction of $\mathrm{MPO}+\mathrm{H}_{2} \mathrm{O}_{2}+\mathrm{Cl}^{-} / \mathrm{Br}^{-}$with polyunsaturated phospholipids occurs if the incubation medium lacks the enzyme or one of the substrates $\left(\mathrm{H}_{2} \mathrm{O}_{2}\right.$ or halide), or contains sodium azide (MPO inhibitor), taurine, or Met (scavenger of $\mathrm{HOCl}$ and $\mathrm{HOBr}$ ). It indicates that polyunsaturated phospholipids are converted into lysoderivatives 
under the action of $\mathrm{HOCl}$ or $\mathrm{HOBr}$ formed in the MPOcatalyzed reaction $[77,80]$.

The reaction of primary RHS with the unsaturated bond of plasmalogen is of particular interest. Plasmalogens comprise $\sim 4.5 \%$ of all phospholipids in LDLs [84]. In plasmalogen, the glycerol hydroxyl group in the sn-1 position is connected through the ether bond with the long aliphatic chain containing the $-\mathrm{HC}=\mathrm{CH}-$ double bond in the $\alpha$-position, which distinguishes plasmalogens from other phospholipids (Fig. 3). This alkenyl ether bond is a target for primary RHS. Plasmalogen interaction with $\mathrm{HOCl}$ (or $\mathrm{HOBr}$ ) results in the formation of lysophosphatidylcholine like that via the phospholipase $\mathrm{A}_{2}$-independent mechanism and aldehyde halogenated at the second position (the first stage in Fig. 3) [51, 85, 86].

A similar reaction was observed when RHS were generated by $\mathrm{MPO}+\mathrm{H}_{2} \mathrm{O}_{2}+\mathrm{Cl}^{-} / \mathrm{Br}^{-}$or activated neutrophils. $\mathrm{HOBr}$ reacted with the plasmalogen alkenyl ether bond at neutral $\mathrm{pH}$, unlike $\mathrm{HOCl}$ that reacted only at acidic $\mathrm{pH}$ values. If $\mathrm{Cl}^{-}$and $\mathrm{Br}^{-}$were simultaneously present in the reaction mixture as MPO substrates, the main product was 2-bromoaldehyde [51, 85].

Simultaneous presence of plasmalogen and unsaturated phosphatidylcholine in the reaction mixture led to the preferential generation of lysophosphatidylcholine from plasmalogen followed by the formation of the unsaturated bond chlorohydrin in the lysophosphatidylcholine acyl chain [87]. When plasmalogen contained a monounsaturated fatty acid in the sn-2 position, lysophosphatidylcholine and 2-halogenoaldehyde were formed at the first stage. And only at the second stage, the monounsaturated lysophosphatidylcholine was converted to its halogenohydrin (Fig. 3) [86, 87]. Reactions of $\mathrm{HOCl}$ and $\mathrm{HOBr}$ with the plasmalogen alkenyl ether bond are much faster than with the unsaturated bond of the phospholipid acyl chain [88]. However, if a polyunsaturated (e.g., docosahexaenoic) acid is present in the sn-2 position of plasmalogen, the reaction with $\mathrm{HOCl}$ results not only in the formation of 2-chloroaldehyde but also in subsequent cleavage of the polyunsaturated acid with the generation of glycerophosphocholine (probably via the mechanism described above for polyunsaturated phosphatidylcholine) [86].

Similar reactions take place in LDLs. Incubation of LDLs in the presence of MPO $+\mathrm{H}_{2} \mathrm{O}_{2}+\mathrm{Cl}^{-}$results in accumulation of 2-chlorohexadecanal and 2-chloroctadecanal, as well as chlorohydrins of unsaturated lysophosphatidylcholines. When LDLs were incubated with activated monocytes, the content of 2-chloraldehydes increased severalfold in both LDLs and the cells [50].
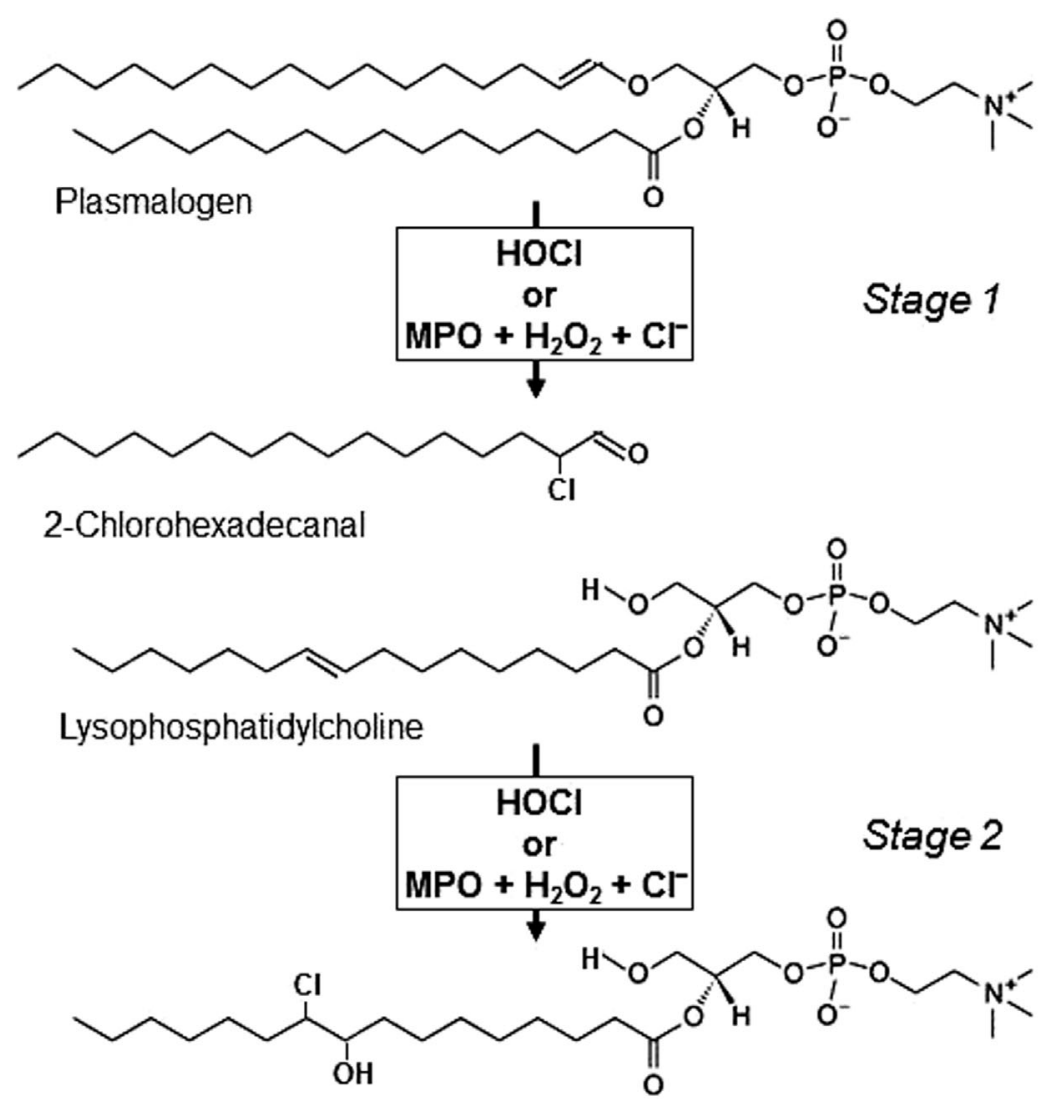

Lysophosphatidylcholine-Chlorohydrin

Fig. 3. Plasmalogen modification by $\mathrm{HOCl}$ or $\mathrm{MPO}+\mathrm{H}_{2} \mathrm{O}_{2}+\mathrm{Cl}^{-}$. 


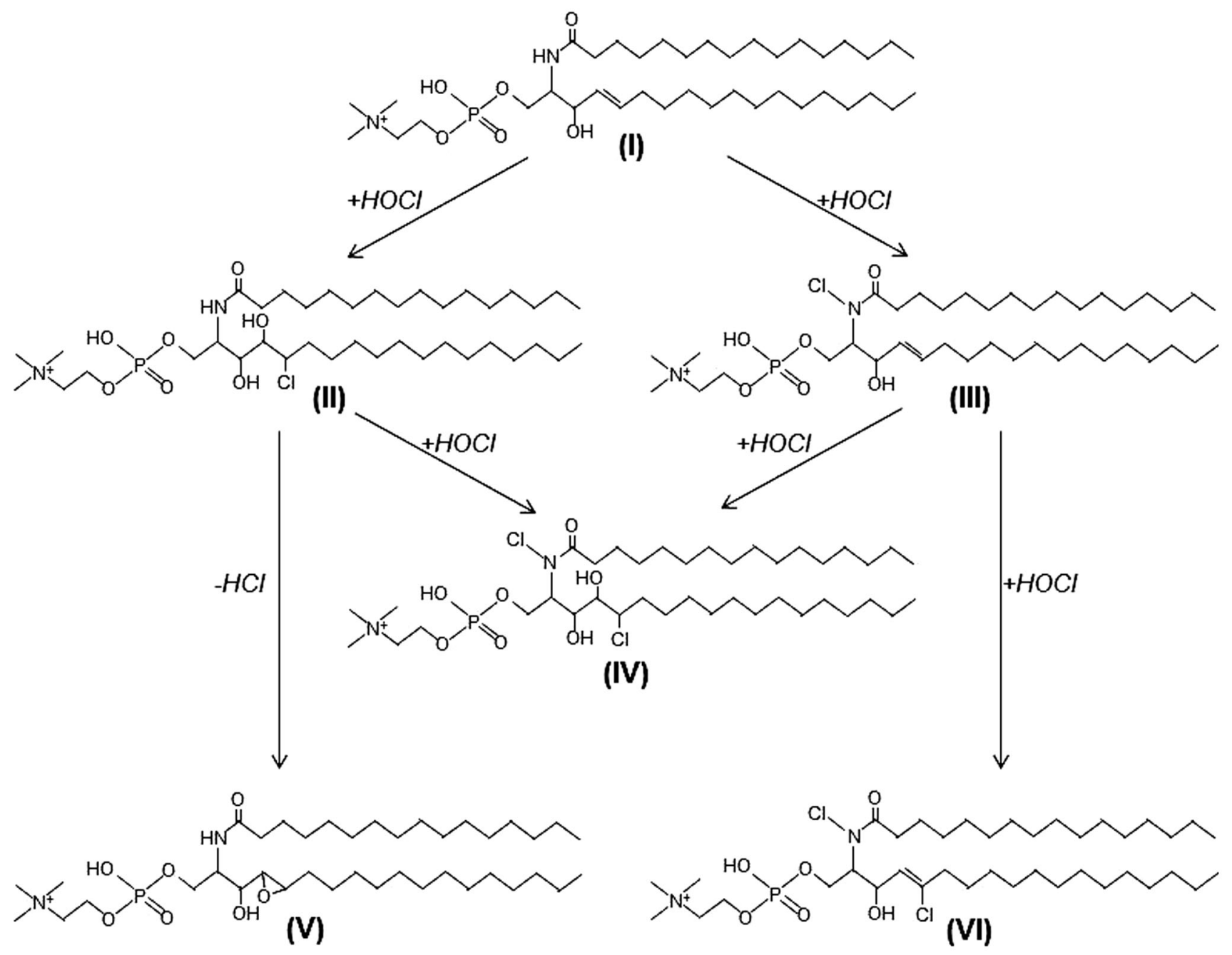

Fig. 4. Sphingomyelin modification by $\mathrm{HOCl}$.

These results demonstrate that by producing $\mathrm{HOCl} / \mathrm{HOBr}$, MPO mimics the function of phospholipase through the formation of chloro- or bromohydrins from polyunsaturated phospholipids, followed by spontaneous hydrolysis of the ester bond with the generation of lysophospholipids. The latter are also formed as a result of cleavage of the alkenyl ether bond in plasmalogen under the action of $\mathrm{HOCl} / \mathrm{HOBr}$ (Fig. 3). Using mass spectrometry and ${ }^{31} \mathrm{P}-\mathrm{NMR}$, it was shown that the content of lysophosphatidylcholine increased when LDLs were incubated in the presence of $\mathrm{HOCl}$ [89]. These reactions can have biological significance. On one hand, it is known that LDLs contain lysophosphatidylcholine in sufficiently large quantities ( $\sim 50 \mu \mathrm{g}$ per mg protein), and its content in LDLs increases with atherosclerosis progression [90, 91]. On the other hand, lysophosphatidylcholine is involved in the regulation of the activity of platelets and endothelial cell, which makes it an atherothrombotic molecule [92].
The second most prevailing phospholipid in LDLs after phosphatidylcholine ( $\sim 900 \mu \mathrm{g}$ per $\mathrm{mg}$ protein) is sphingomyelin ( $\sim 400 \mu \mathrm{g}$ per mg protein). Sphingomyelin is the only human phospholipid that does not contain glycerol but has the amino alcohol sphingosine. The fatty acid in sphingomyelin is attached to the sphingosine amino group, while the phosphocholine polar group is attached to the sphingosine hydroxyl group (Fig. 4, (I)). The RHS targets in the sphingomyelin molecule are the sphingosine double bond and the hydrogen atom of the amide bond. The rate constant of the $\mathrm{HOCl}$ reaction with sphingomyelin was estimated as $18.7 \pm 3.05 \mathrm{M}^{-1} \cdot \mathrm{s}^{-1}$ [93], which is faster than the reaction between $\mathrm{HOCl}$ and unsaturated bonds of acyl chains $\left(0.56 \mathrm{M}^{-1} \cdot \mathrm{s}^{-1}\right.$ [94]). Using MALDI-TOF-mass spectrometry, it was shown that $\mathrm{HOCl}$ added as a reagent or produced by MPO transforms sphingomyelin into its chlorine derivative as a result of $\mathrm{HOCl}$ addition to the sphingosine double bond (Fig. 4, stage (II)) or substitution of the amide bond 
hydrogen atom with the chlorine atom (Fig. 4, stage (III)). Under the action of two $\mathrm{HOCl}$ molecules, both reactions can proceed with the formation of compound (IV) (Fig. 4). Epoxide (V) resulting from chlorohydrin dehydrochlorination (Fig. 4) and chlorine derivative $-\mathrm{CH}=\mathrm{CCl}-(\mathrm{VI})$ formed by the replacement of hydrogen atom of the $-\mathrm{CH}=\mathrm{CH}-$ double bond with chlorine (Fig. 4) were minor products. Traces of (V) and (VI) were also detected in the reaction of unsaturated bonds of phospholipids acyl chains with primary RHS [78, 81, 82]. Chlorinated sphingomyelin derivatives produce significant effects on the cells, including initiation of reactive oxygen species production, uncoupling of the mitochondrial transmembrane potential, apoptosis induction, and DNA damage [93].

In cholesterol, the only target for hypohalous acids is the double bond at the 5,6 position of the steroid nucleus. Using thin-layer chromatography, NMR, and mass spectrometry, it was found that adding $\mathrm{HOCl}$ to the cholesterol-containing phospholipid liposomes leads to the formation of chlorine derivatives, mainly $\alpha$ - and $\beta$-isomers of chlorohydrins $[95,96]$. The same products were formed in LDLs treated with $\mathrm{HOCl}$ or in the presence of $\mathrm{MPO}+\mathrm{H}_{2} \mathrm{O}_{2}+\mathrm{Cl}^{-}$[97]. Addition of catalase and $\mathrm{HOCl}$ scavengers prevented formation of such products, indicating involvement of $\mathrm{MPO}$ and $\mathrm{HOCl}$ in the reaction [95]. Unlike chlorohydrins of aliphatic hydrocarbon chains, cholesterol chlorohydrins are unstable and convert into epoxides by dehydrochlorination. Hydrolysis and further oxidation of $\alpha$ - and $\beta$-epoxides leads to the formation of cholesterol hydroxy- and keto- derivatives $[98,99]$. The reaction of $\mathrm{HOBr}$ with the cholesterol double bond proceeds similarly to analogous reaction with $\mathrm{HOCl}$ but requires smaller amounts of $\mathrm{HOBr}$ compared to $\mathrm{HOCl}[100]$.

The free radical mechanism of the unsaturated lipid modification by RHS is described in detail in reviews [25, 101]. Here, we discuss only the results confirming the existence of this mechanism in LDLs. The first works on the LPO induced in LDLs by RHS and MPO $+\mathrm{H}_{2} \mathrm{O}_{2}+$ $\mathrm{Cl}^{-}$were conducted in early 1990 s $[102,103]$. The following studies have shown that LDL incubation with primary RHS or in the presence of MPO $+\mathrm{H}_{2} \mathrm{O}_{2}+\mathrm{Cl}^{-}$results in the formation of typical primary molecular products, such as diene conjugates and hydroperoxides, usually detected by traditional methods of LPO induction [102, 104], secondary products of carbonyl nature, that react with 2-thiobarbituric acid [101-103, 105-108], and end products that fluoresce in the visible light (e.g., Schiff bases). The latter are formed by the interaction of oxidized lipids with proteins (reaction (7)) [105, 108]. Free radical traps, such as $\alpha$-tocopherol and butylated hydroxytoluene, in micromolar concentrations completely blocked the RHS-induced LPO [42, 106], which confirmed its free-radical mechanism. By penetrating into the LDL lipid phase, $\mathrm{HOCl}$ caused degradation of lipid- soluble antioxidants (carotenoids, $\alpha$-tocopherol), reducing LDL resistance to LPO [42, 71, 109, 110]. RHS can initiate LPO through the reaction of $\mathrm{HOCl}$ or $\mathrm{HOBr}$ with hydroperoxides (rate constants, 10.8 and $8.9 \mathrm{M}^{-1} \cdot \mathrm{s}^{-1}$ for $\mathrm{HOCl}$ and $\mathrm{HOBr}$, respectively [111]). Hydroperoxides are always present in trace amounts in unsaturated lipid [112] and can form peroxyl and alkoxyl radicals in the reaction with hypohalous acids [111, 113-120]. Elevated levels of LDLs containing LPO products have been found in the blood of CVD patients [121, 122].

It is known that some compounds promote LPO in LDLs. For example, hemoglobin modified by $\mathrm{HOCl}$ increases accumulation of LPO products in LDLs by a factor of $\sim 2$ compared to the native protein. The increase in the prooxidant capacity of hemoglobin after incubation with $\mathrm{HOCl}$ is associated with heme destruction, release of $\mathrm{Fe}^{2+}$ ion, and its subsequent oxidation by $\mathrm{HOCl}$ to $\mathrm{Fe}^{3+}[123]$. The last reaction generates the ${ }^{\circ} \mathrm{OH}$ radical, an extremely efficient LPO inducer [124].

Nitrite also promotes HOCl-induced LPO in LDLs [42] through the formation of nitrile chloride $\left(\mathrm{NO}_{2} \mathrm{Cl}\right)$ in reaction (2) with further decomposition into free radicals in reaction (3). Addition of butylated hydroxytoluene (free radical trap) to the reaction mixture significantly inhibited accumulation of LPO products in LDLs that indicates the radical mechanism of peroxidation in the presence of $\mathrm{HOCl}+\mathrm{NO}_{2}^{-}$[42]. A mixture of $\mathrm{HOCl}+\mathrm{NO}_{2}^{-}$causes tyrosyl radical formation [44] in proteins. Tyrosyl radicals are also formed in the peroxidase cycle of MPO by Tyr oxidation with Compounds I and II (Fig. 2). Tyrosyl radical is a known inducer of LPO free radical reactions in LDLs [125]. Another mechanism of the MPO-mediated LPO activation in LDLs is not associated with the formation of $\mathrm{HOCl}$ and $\mathrm{NO}_{2} \mathrm{Cl}$. It is $\mathrm{NO}_{2}^{-}$oxidation to the $\mathrm{NO}_{2}^{-}$ radical in the MPO peroxidase cycle [44].

$\mathrm{NH}_{2}$-groups of Lys also contribute to the HOClinduced LPO in LDLs by reacting with $\mathrm{HOCl}$ with the formation of Lys chloramine that decomposes in reaction (5) to the N-centered radical. The latter initiates LPO in LDLs [104]. Similar processes occur in the reaction of $\mathrm{NH}_{2}$-group of phosphatidylethanolamine with $\mathrm{HOCl}$, which also results in the formation of $\mathrm{N}$-centered radical [126].

Reactions of phospholipid polar heads with RHS. The polar heads of phospholipids in LDLs are mainly choline phosphate, ethanolamine phosphate, and serine phosphate. Neither $\mathrm{HOCl}$ nor $\mathrm{HOBr}$ react at a noticeable rate with the quaternary nitrogen of phosphatidylcholine [71, $72,75,77,78,82,83,127,128]$. In contrast, the $\mathrm{NH}_{2-}$ groups of ethanolamine phosphate and serine phosphate easily react with $\mathrm{HOCl}$ and $\mathrm{HOBr}$ with the formation of chlor- and bromamines, respectively (the table). Chloramines of phosphatidylethanolamine and phosphatidylserine differ considerably in their stability due to presence of carboxyl group in the position next to the $\mathrm{NH}_{2}$-group in serine phosphate. Such chloramines 
quickly decompose with the formation of aldehydes. Figure 5 shows the conversion of phosphatidylserine and phosphatidylethanolamine amino groups in the interaction with $\mathrm{HOCl}$. The latter transforms phosphatidylethanolamine into mono- and then dichloramine $[126,129]$ which undergoes dehydrochlorination accompanied by the homolytic cleavage of the $\mathrm{N}-\mathrm{Cl}$ bond with the formation of the N-centered radical (Fig. 5) [126]. The difference in the mechanisms of conversion of phosphatidylethanolamine and phosphatidylserine chloramines led to the hypothesis on the MPO-dependent regulation of LPO of unsaturated phospholipids [126]. It was found that the presence of phosphatidylethanolamine in unsaturated phosphatidylcholine liposomes contributes to the accumulation of LPO products under the action of $\mathrm{HOCl}$ due to the formation of $\mathrm{N}$-centered radical acting as an LPO inducer. In contrast, inclusion of phosphatidylserine in the phosphatidylcholine liposomes inhibited HOCl-induced LPO as a result of decrease in $\mathrm{HOCl}$ concentration due to its interaction with the amino groups. In this case, the generated products are uncapable of LPO initiation (Fig. 5 and [126]).

The reaction of unsaturated phosphatidylethanolamine with $\mathrm{HOCl}$ or $\mathrm{HOBr}$ involves the attack on the polar head $\mathrm{NH}_{2}$-groups and the $-\mathrm{CH}=\mathrm{CH}$ - bonds of acyl chains. The $\mathrm{NH}_{2}$-groups enter the reaction with $\mathrm{HOCl}$ first, and only after all amines are converted to dichloramines (Fig. 5), chlorohydrin formation begins [130], that is due to a significant difference (by 3-4 orders of magnitude) in the rate constants of the $\mathrm{HOCl}$ reactions with the $\mathrm{NH}_{2}$-group and unsaturated $-\mathrm{HC}=\mathrm{CH}-$ bond of phosphatidylethanolamine (the table and [58]). Formation of bromamines and bromohydrins in the reaction of unsaturated phosphatidylethanolamine with $\mathrm{HOBr}$ starts almost simultaneously [130]. The rate constants of these reactions differ insignificantly (the table and [59]).

Modification of carbohydrates. Carbohydrates are found in LDLs as components of glycolipids and ApoB100. ApoB100 is a glycoprotein containing Nacetylglucosamine, galactose, mannose, and sialic acid at a molar ratio of $\sim 4: 2: 5: 2$ [131]. ApoB100-associated glycoconjugates are represented by two main types: biantennal sialylated chains and highly mannosylated chains containing N-acetylglucosamine. The ApoB100 molecule contains 5-6 highly mannosylated and 8-10 sialylated conjugates bound to the protein through Asn residues (according to [132]). The carbohydrate composition of the LDL lipid fraction differs from the composition of protein-associated carbohydrates. Thus, LDL glycolipids contain glucose and $\mathrm{N}$-acetylgalactosamine, but not mannose [131].

Primary RHS either do not react with sugars lacking nitrogen atoms in their molecules (e.g., ribose, glucose,
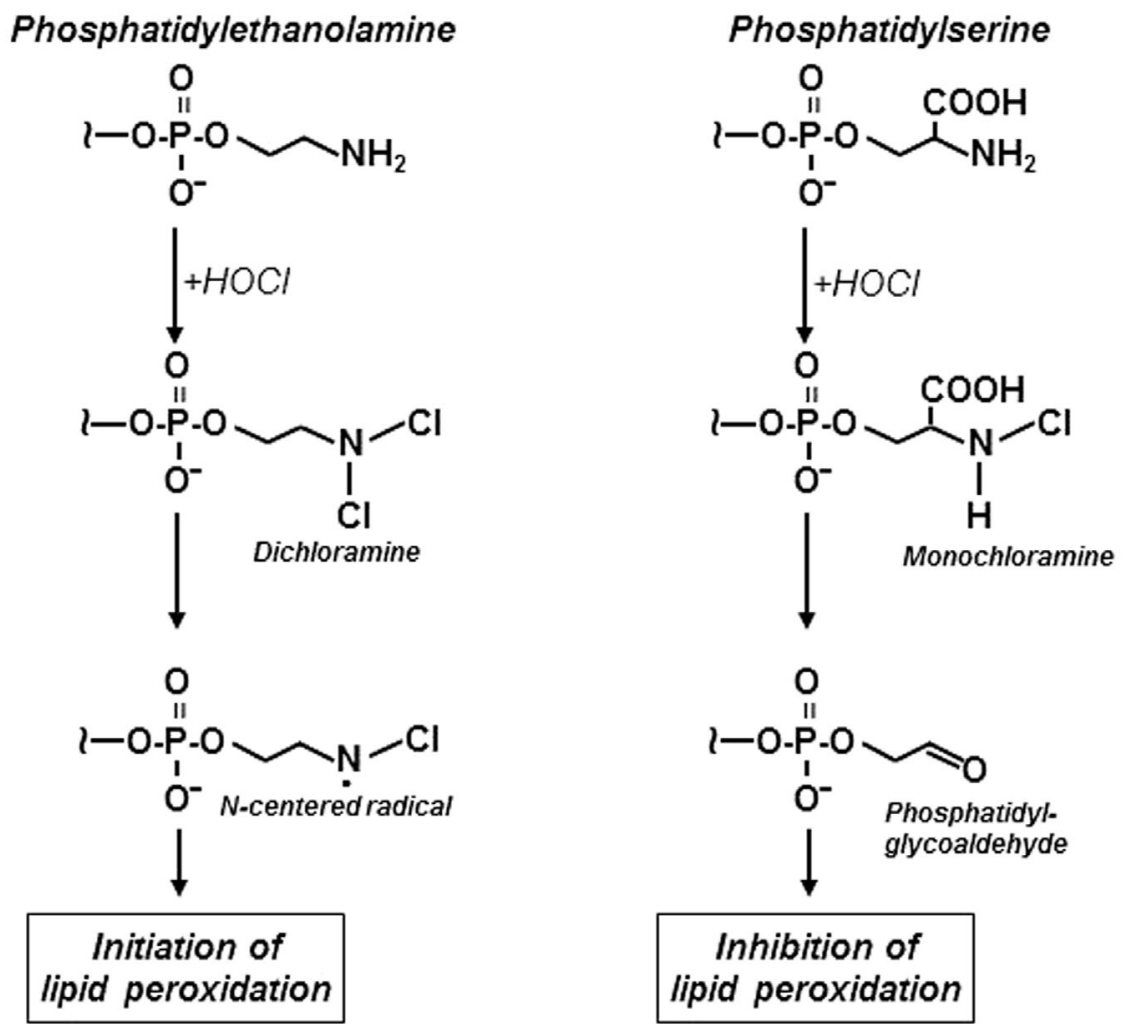

Fig. 5. Modification of phosphatidylethanolamine and phosphatidylserine by $\mathrm{HOCl}$ formed in the MPO-catalyzed reaction. 


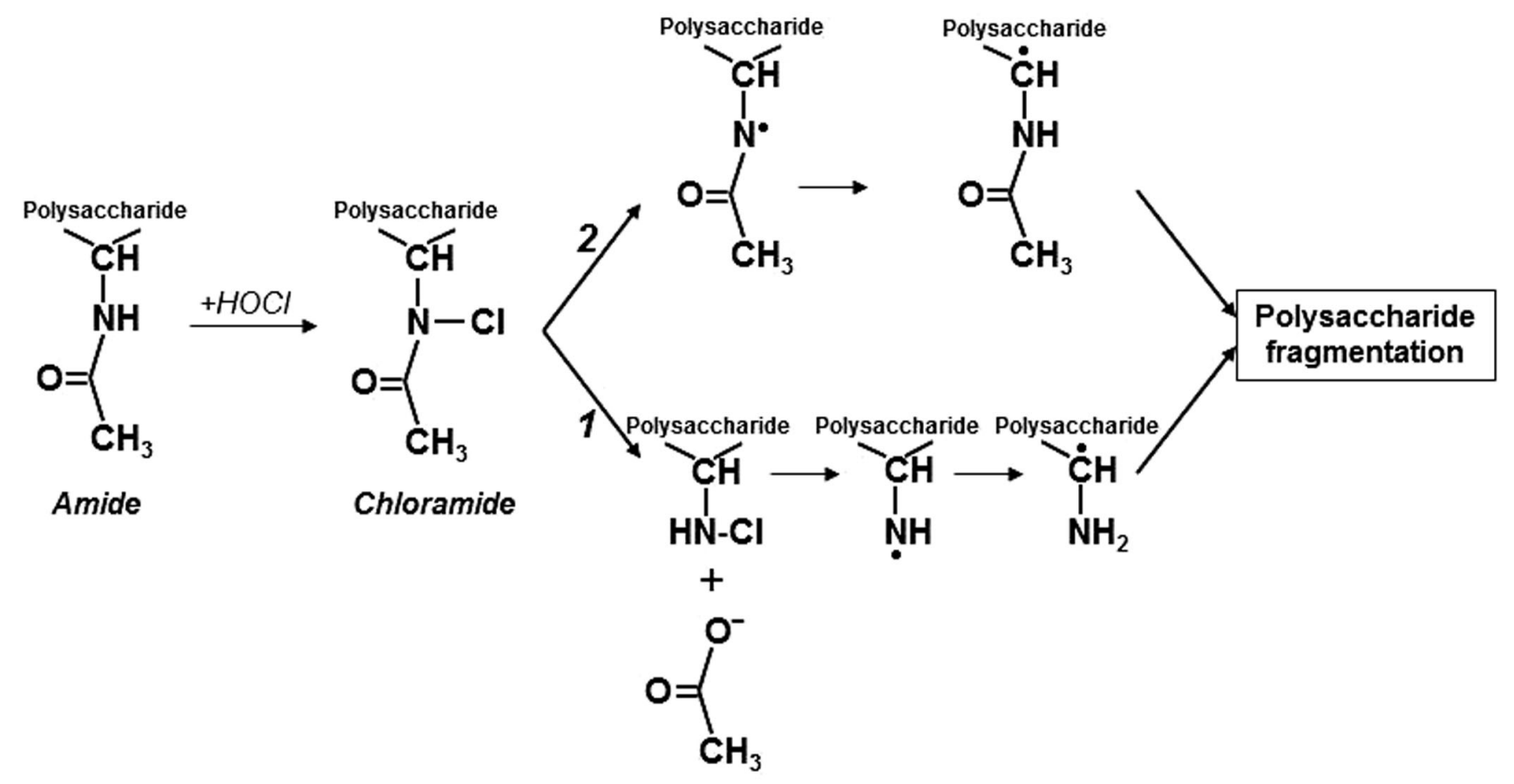

Fig. 6. $\mathrm{HOCl}$ reaction with $\mathrm{N}$-acetylated amino sugar.

glucuronic acid) or react extremely slowly with them $[133,134]$. At the same time, RHS react at a high rate with $\mathrm{N}$-acetylated amino sugars [41, 134]. N-acetylglucosamine, $\mathrm{N}$-acetylgalactosamine, and sialic acids are the RHS targets in ApoB100 and LDL glycolipids. It was established that at the first stage of the reaction, the $\mathrm{N}$ acetamide group hydrogen atom is replaced by a halogen atom with the formation of chlor- or bromamide. Figure 6 shows the reaction of $\mathrm{N}$-acetylated amino sugars with $\mathrm{HOCl}$. The resulting chloramide is slowly hydrolyzed to monochloramine and acetate (reaction 1 in Fig. 6) [135] or transformed to the $\mathrm{N}$-centered amidyl radical as a result of homolytic cleavage of the $\mathrm{N}-\mathrm{Cl}$ bond (reaction 2 in Fig. 6) [136, 137]. As mentioned above (reaction 1 in Fig. 6 and reaction (3)), the $\mathrm{N}-\mathrm{Cl}$ bond in monochloramine undergoes homolytic cleavage with the formation of $\mathrm{N}$-centered radical. Then, both $\mathrm{N}$-centered radicals are isomerized to $\mathrm{C}$-centered radicals on the $\mathrm{C}$-atom in the second position of the ring and on the $\mathrm{C}$-atom of the nearby ring, which leads to the ring fragmentation of the polysaccharide chain [135-137]. Similar processes were observed in the reaction of glycosaminoglycans with $\mathrm{HOBr}$ [138]. Ions of transition metals contribute to the homolytic cleavage of the $\mathrm{N}-\mathrm{Cl}$ bond [137, 138]. Superoxide anion radical significantly accelerates the break of the $\mathrm{N}-\mathrm{Cl}$ bond presumably due to the reduction of transition metal ions [139, 140].

It was suggested that desialylation transforms LDLs into their pro-atherogenic form [141, 142]. Desialylated LDLs are actively captured by subendothelial cells, turning them into the foam cells [20]. Desialylated LDLs were isolated from the blood of patients with atherosclerosis [20, 141]. The authors of this hypothesis suggest that LDL desialylation is catalyzed by the trans-sialidase enzyme [143]. The results described in this section indicate that at least partially, the cleavage of glycoconjugates from the LDLs can occur under the action of RHS formed in the MPO-catalyzed reactions.

RHS interaction with antioxidants. LDLs contain many lipid-soluble antioxidants. On average, $1 \mathrm{~mol}$ of LDL contains $6.37 \mathrm{~mol}$ of $\alpha$-tocopherol, $0.93 \mathrm{~mol}$ of $\gamma$ tocopherol, $0.1 \mathrm{~mol}$ of ubiquinol-10 (reduced coenzyme $\mathrm{Q} 10)$, and carotenoids, such as $\beta$-carotene $(0.53 \mathrm{~mol}), \alpha$ carotene $(0.22 \mathrm{~mol})$, lycopene $(0.29 \mathrm{~mol})$, cryptoxanthin $(0.25 \mathrm{~mol})$, and trace amounts of lutein, anhydrolutein, zeaxanthin, and canthaxanthin [110, 144]. All these antioxidants are destroyed to a different degree by adding $\mathrm{HOCl}$ to the LDLs. First, ubiquinol-10 disappears, then lycopene, then $\alpha$-tocopherol and $\beta$-carotene [145]. Comparison of carotenoids (cis- and trans-lycopenes, $\alpha-$ and $\beta$-carotenes) and their oxy-derivatives (zeaxanthin, $\alpha$ - and $\beta$-cryptoxanthins, cis- and trans-anhydroluteins) showed that, the former are more efficient $\mathrm{HOCl}$ scavengers. The content of these carotenoids in LDLs is decreased by $25 \%$ by treatment with $36-52 \mathrm{HOCl}$ molecules per one LDL particle [110]. However, considering the number of antioxidant molecules per LDL particle shows that $50 \%$ oxidation of $\alpha$-tocopherol required $\sim 125$-fold, ubiquinol-10 and lycopene $\sim 2000$-fold, and $\beta$-carotene $\sim 2500$-fold molar excess of $\mathrm{HOCl}$. The second-order rate constants of the reaction of Trolox ( $\alpha$-tocopherol water-soluble analog), ubiquinol-0 
(ubiquinol-10 analog), and $\beta$-carotene with $\mathrm{HOCl}$ are significantly lower than those for the reaction of functional groups of some amino acid residues (the table and $[55,58,146])$.

Nitrite promote the $\mathrm{HOCl}$-induced degradation of $\alpha$-tocopherol and $\beta$-carotene in LDLs [42], which might be explained by the generation of ${ }^{\circ} \mathrm{NO}_{2}$ and $\mathrm{Cl}^{\circ}$ radicals in reaction (2) and (3). These radicals react with $\alpha$-tocopherol and $\beta$-carotene faster than $\mathrm{HOCl}$ [42].

The rate constants of the similar reaction of Trolox and ubiquinol- 0 with $\mathrm{HOBr}$ are $\sim 50$ and $\sim 2000$ times higher, respectively, than with $\mathrm{HOCl}$ [59]. Even at the $\mathrm{HOBr} / \mathrm{LDL}$ molar ration of 2000 , only $0.4 \%$ of $\mathrm{HOBr}$ reacts with antioxidants, while the rest $\mathrm{HOBr}$ molecules react with lipids (56.6\%) and proteins (43.0\%) [59]. Therefore, it is unlikely that antioxidants are the major targets of RHS. This suggestion was confirmed by the study [147] that demonstrated that neither $\sim 8$-fold enrichment nor $\sim 6$-fold depletion of LDLs with $\alpha$-tocopherol produced effect on the HOCl-induced modification of Trp and Lys residues of ApoB100.

\section{MODIFICATION OF LDL STRUCTURE IN THE REACTIONS WITH RHS}

The reactions of RHS with the functional groups of ApoB100, lipids, antioxidants, and carbohydrates in LDLs are unavoidably accompanied by changes in the physicochemical properties and structural organization of the LDL particles. Spin-labeled analogues of stearic acid with a paramagnetic fragment at the 5 th, 12 th, or 16 th $\mathrm{C}$-atoms were used to assess the changes in the physicochemical properties of the phospholipid monolayer on the LDL surface. These probes made it possible to obtain the information on the physicochemical characteristics of the lipid phase at different distances from the LDL particle surface. Adding $\mathrm{HOCl}$ to the LDLs caused a decrease in the mobility of the phospholipid fatty acid chains and, at the same time, increased the polarity of their microenvironment up to the 12th $\mathrm{CH}_{2}$-group of the fatty acid chain (which corresponded to the depth of $\sim 1.7 \mathrm{~nm}$ from the LDL surface). Only at the $\mathrm{HOCl}$ concentration exceeding $1 \mathrm{mM}$, significant changes in the studied parameter were observed in the LDL deeper regions (in the region of the 16th $\mathrm{CH}_{2}$-group) [148].

$\mathrm{HOCl}$-induced changes in the ApoB100 structure were studied using the spin-tag 3-maleimidoproxil covalently linked to the protein SH-groups. The EPR spectrum of LDLs labeled with this spin tag represented a superposition of two signals, wide and narrow, corresponding to the strongly and weakly immobilized label, respectively, which indicated the presence of two populations of SH-groups in the LDL, with higher and lower mobility. Adding $\mathrm{HOCl}$ to the LDLs decreased the fraction of strongly immobilized spin label and increased the fraction of weakly bound label, suggesting an increase in the mobility of ApoB100 labeled sites upon reaction with $\mathrm{HOCl}$ [149].

LDL particles are characterized by the negative surface potential of $-16--17 \mathrm{mV}[150,151]$. Using electrophoresis and EPR with paramagnetic $\mathrm{Mn}^{2+}$ cations, it was shown that reaction with primary RHS increases the negative surface charge and electrophoretic mobility of LDLs [145, 147, 151]. This can be mainly due to the transformation of positively charged amino acid residues Lys, His, and Arg [55, 56], as well as $\mathrm{NH}_{2}$-groups of the ethanolamine phosphate and serine phosphate of phospholipids located at the surface of LDL particles [58, 59] into halogenamines or other neutral products. The alterations in the local charge distribution on the LDL surface can induce aggregation of LDL particles. Incubation of LDLs with $\mathrm{HOCl}$ or $\mathrm{MPO}+\mathrm{H}_{2} \mathrm{O}_{2}+\mathrm{Cl}^{-}$is accompanied by an increase in the average LDL particle size, as shown in many in vitro experiments $[152,153]$. Cultured smooth muscle cells from the intima of healthy human aorta accumulate cholesterol from $\mathrm{HOCl}$-modified LDLs [153]. As a rule, lipid accumulation by the cells increases with an increase in the average size of LDL particles [17, 20, 142]. Similar spherical lipid inclusions with a diameter of 100-400 $\mathrm{nm}$ have been repeatedly found in the arterial intima affected by atherosclerosis $[154,155]$.

Three possible mechanisms for the MPO-induced formation of intermolecular crosslinks in ApoB100, which can be the cause of the LDL particle aggregation, were described in the previous chapter. Hazell et al. showed [60] that LDL aggregation in the human blood induced by $\mathrm{HOCl}$ or $\mathrm{MPO}+\mathrm{H}_{2} \mathrm{O}_{2}+\mathrm{Cl}^{-}$was accompanied by the increase in the content of carbonyl compounds and simultaneous disappearance of Lys residues. When the amino groups of Lys in ApoB100 in LDLs were preventively blocked by reducing methylation, no aggregation of LDL particles was observed. It was found that LDL aggregation occurs according to the first described mechanism (reactions (4), (6) and (7) in the previous chapter) through the conversion of Lys chloramines into aldehydes with subsequent formation of Schiff bases type intermolecular crosslinks.

High-molecular-weight protein complexes resistant to heat denaturation in the presence of sodium dodecyl sulfate and 1,4-dithiothreitol were found in the human blood LDLs after reaction with $\mathrm{HOCl}$. Such resistance indicated formation of covalent but not disulfide crosslinks most likely via the first mechanism (see previous chapter). An increase in the $\mathrm{HOCl}$ concentration was accompanied by the increase in the content of di-Tyr (third mechanism, previous chapter). However, the observed amount of di-Tyr was not enough to explain all the existing intermolecular crosslinks in the LDLs [156].

The possibility of formation of the intra- and intermolecular $\mathrm{S}-\mathrm{S}$ and $\mathrm{S}-\mathrm{N}$ crosslinks in LDLs by the second mechanism (reaction (8) in the previous chapter) was 
demonstrated using synthetic peptides containing Cys and Lys residues [66]. Incubation of these peptides with $\mathrm{HOCl}$ resulted in the generation of intra- and intermolecular sulfene amides according to reaction (8), which were then oxidized to sulfine amides and sulfone amides. Hence, the observed $\mathrm{S}-\mathrm{N}$ crosslinks were formed by the $\mathrm{HOCl}$-mediated interaction between the $\mathrm{SH}$-groups of Cys and $\mathrm{NH}_{2}$-groups of Lys. Disulfides were also found among the products of sulfenyl chloride reaction with the $\mathrm{SH}$-groups of Cys (reaction (8) in previous chapter) [66].

Therefore, RHS formed in the MPO-catalyzed reaction can modify the physicochemical properties and structural organization of the surface proteolipid layer of LDL particles and stimulate LDL aggregation and their transformation into proatherogenic form.

\section{INTERACTION BETWEEN MPO AND LDL}

Given that MPO is extremely polycationic $(\mathrm{p} I \sim 10)$ and LDL surface is negatively charged [150, 157], it can be assumed a priori that they are capable of interacting with each other. The interaction between MPO and LDLs was for the first time demonstrated by co-precipitation with phosphotungstate and studying the electrophoretic mobility of the coprecipitates [158]. The presence of the cationic detergent cetrimide, as well as an increase in the $\mathrm{NaCl}$ concentration to $0.3 \mathrm{M}$ or $\mathrm{pH}$ decrease to 3.6 , prevented the interaction, which suggests the electrostatic nature of MPO binding to LDLs [159]. The binding of MPO to the surface of LDLs and very low-density lipoproteins (VLDLs) was confirmed by electrophoresis, gel filtration, and photon correlation spectroscopy. It was determined that the average diameter of MPO-LDL and MPO-VLDL complexes was $28.0 \pm 1.9$ and $85.9 \pm$ $8.9 \mathrm{~nm}$, respectively [160].

The absence of lipids in the contact area between MPO and LDL was demonstrated using spin-labeled derivatives of fatty acid that incorporated into the LDL phospholipid monolayer and provided positioning of the paramagnetic center at different distances from the surface. MPO interaction with LDLs did not significantly affect the parameters of the EPR spectra of these probes, which indicated that the interaction between MPO and LDLs does not involve lipids. Studying the distribution of paramagnetic $\mathrm{Mn}^{2+}$ cations between the LDL surface and water environment in the dependence of MPO adding demonstrated that the interaction between MPO and LDLs does not lead to significant changes in the negative surface charge of LDL particle. These results suggest that the contact area between MPO and LDL is extremely small and does not involve phospholipids, the main carriers of negatively charged groups on the LDL surface [159].

Interestingly, MPO did not interact with high-density lipoproteins (HDLs). Since LDLs and VLDLs differ from HDLs in the ApoB100 content on their surface, we believe that MPO binds to this protein. The fact that antibodies against ApoB100 displace MPO from the complex with LDLs or VLDLs confirms this hypothesis [160]. Analysis of the ApoB100 amino acid sequence for the potential MPO-binding sites enriched with negatively charged resides and lacking positively charged amino acids identified three peptides: ${ }^{1}$ EEEMLEN $^{7}$, ${ }^{53} \mathrm{VELEVPQ}^{59}$, and ${ }^{445}$ EQIQDDCTGDED ${ }^{456}$. We demonstrated that only the ${ }^{445}$ EQIQDDCTGDED ${ }^{456}$ peptide disrupted the MPO-LDL complex and, therefore, could represent the MPO-binding site in ApoB100. The specific interaction of this peptide with MPO was also confirmed by gel filtration. Therefore, ${ }^{445}$ EQIQDDCTGDED ${ }^{456}$ causes dissociation of the MPO-LDL complex by interacting with MPO and not with the LDL [159].

The association of MPO with the LDL surface is accompanied by the increase in the enzyme activity [63], which contributes to the LDL surface modification by RHS formed in the MPO-catalyzed reactions. This modification reduces the affinity of ApoB100 for the ApoBand ApoE-receptors and increases the affinity of mLDLs for the scavenger receptors of macrophages and monocytes. The latter leads to the progressive accumulation of intracellular cholesterol and its esters and transformation of macrophages and monocytes into foam cells [161].

The plasma protein ceruloplasmin (CP) interacts with MPO and inhibits both peroxidase and halogenating activities of the enzyme [162-164]. CP retains its ability to inhibit MPO even when MPO is associated with the LDL surface and forms the CP/MPO/LDL(VLDL) [160]. We showed that the ${ }^{445}$ EQIQDDCTGDED ${ }^{456}$ peptide (which uncouples the interaction of MPO with LDL), as well as physiological modulators of the MPO halogenating activity, such as thiocyanate and $\mathrm{CP}$, decreased the accumulation of cholesterol by monocytes and macrophages in the presence of LDLs modified by $\mathrm{HOCl}$ and $\mathrm{HOBr}$ [161].

Based on the data obtained, we propose a mechanism for the participation of MPO and produced RHS, as well as the ${ }^{445}$ EQIQDDCTGDED ${ }^{456}$ peptide and inhibitors/modulators of MPO halogenating activity (CP and thiocyanate), in the proatherogenic modification of LDLs, activation of monocytes, and formation of foam cells (Fig. 7). The binding of MPO to LDL leads to the site-specific modification of the latter ( 1 in Fig. 7). LDL$\mathrm{Cl}$ (LDL-Br) stimulates leukocytes ( 2 in Fig. 7), provokes respiratory burst, and MPO release by neutrophils and monocytes (3 in Fig. 7). Secreted MPO binds to the LDLs and promotes their damage, thus closing the "vicious circle" of the LDL-Cl (LDL-Br) generation. mLDLs in a complex with MPO are captured by monocytes and macrophages, leading to the accumulation of cholesterol in these cells and their transformation into foam cells (4 in Fig. 7). Inhibitors/modulators of the MPO halogenating activity (CP and thiocyanate), as well 


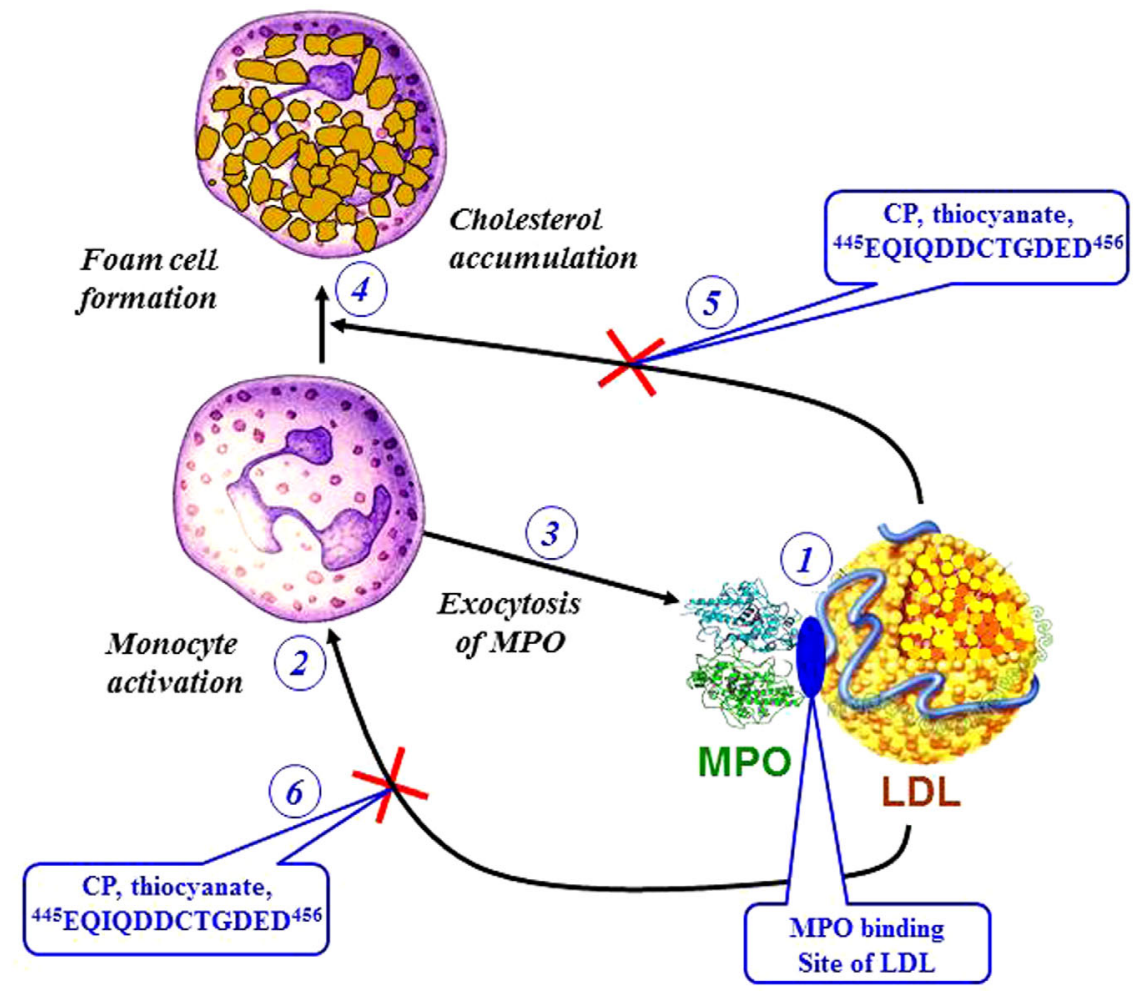

Fig. 7. Participation of MPO, ${ }^{445}$ EQIQDDCTGDED ${ }^{456}$ peptide, and inhibitors/modulators of MPO halogenating activity (CP and thiocyanate) in the atherogenic modification of LDLs, activation of monocytes, and formation of foam cells.

as the inhibitor of the LDL-MPO complex ${ }^{445}$ EQIQDDCTGDED $^{456}$, prevent the oxidative/halogenative modification of LDLs. On one hand, this reduces LDL uptake and accumulation of intracellular cholesterol (5 in Fig. 7); on the other hand, it breaks the vicious circle of monocyte (neutrophil) activation and LDL-Cl (LDL-Br) formation (6 in Fig. 7).

These results allow to make an important addition to the scheme describing the role of mLDLs in the formation of atherosclerotic plaques (Fig. 1). The binding of MPO to LDLs and proatherogenic modification of LDL surface start already in the bloodstream. The transformation of LDLs into the proatherogenic form is aggravated after migration of the MPO-LDL complexes into the subendothelial space. This hypothesis is confirmed by detection of ApoB100-containing lipoprotein complexes with MPO in the blood of patients with atherosclerosis [160].

\section{BIOMARKERS OF MPO ACTIVITY AND HALOGENATIVE STRESS IN CARDIOVASCULAR DISEASES}

Epidemiological studies of recent years have shown that high MPO concentration in the human blood is associated with an increased risk of CVD, regardless of classi- cal risk factors, such as troponin $\mathrm{T}$ and $\mathrm{C}$-reactive protein (reviews $[23,165]$ ). Indeed, an increase in the MPO concentration or activity in the blood plasma [166-168], leukocytes [166], and atherosclerotic plaques [169], as well as in the complexes with ApoB100-containing LDLs and VLDLs, has been repeatedly registered in CVD patients [160]. As a rule, an increase in the concentration and/or activity of MPO was accompanied by the accumulation of specific biomarkers in the patient's blood and tissues.

The "ideal" biomarker of the MPO-induced protein modification is 3-chlorothyrosine. This highly stable product is formed in the body by the $\mathrm{HOCl}$ reaction with tyrosine. 3-Chlorothyrosine can be detected by various combinations of methods, such as chromatography, mass spectrometry, NMR, etc. The elevated levels of 3chlorothyrosin have been registered in the human blood plasma during myocardial infarction [170, 171], atherosclerotic plaques and LDLs isolated from them [172, 173], HDLs [174, 175] and apolipoprotein A-I isolated from HDLs and aorta from CVD patients [176], and cardiac tissue homogenate from individuals with atrial fibrillation [177]. It is important to note that the amount of MPO $[170,171]$ and, often, the severity of the disease [176] correlated with the recorded 3-chlorotyrosine levels.

$\mathrm{HOCl} / \mathrm{HOBr}$-modified proteins can be detected by ELISA using monoclonal antibodies. These antibodies 
are very specific and sensitive to the RHS-modified epitopes and do not bind to proteins modified by aldehydes or $\mathrm{Cu}^{2+}$ ions generated in the oxidative stress [178]. RHSmodified proteins were found in atherosclerotic plaques in the aorta [179] and iliac artery [180]. In the latter case, the level of RHS-modified protein correlated with the content of MPO and ApoB100 in the vessel and with the extent of its damage [180].

Chloro- and bromohydrins of aliphatic chains of lipids are specific markers of lipid damage in the halogenative stress. These compounds are very stable and can accumulate in the body in detectible amounts, since the concentration of unsaturated bonds of aliphatic chains is high. The disadvantage of these biomarkers is a relatively low rate of their formation (the table). Using liquid chromatography/mass spectrometry (LC-MS), the authors [181] registered the formation of chlorohydrins (but not hydroperoxides) of oleic, linoleic, and arachidonic acids in the phospholipid fraction of LDLs after incubation with HOCl. Messner et al. [87] detected lysophosphatidylcholine chlorohydrins in human arterial endothelial cells after their treatment with $\mathrm{HOCl}$ using the ESI-MS method. Later, the same authors found a 60 fold increase in the content of lysophosphatidylcholine chlorohydrin in human atherosclerotic plaques compared with the tissue unaffected by atherosclerosis [182]. An alternative approach for detecting tissue damage by RHS formed in the MPO-catalyzed reactions is the use of monoclonal antibodies against chlorohydrins of oleic acid [183].

Aliphatic 2-chloroaldehydes formed in the $\mathrm{HOCl}$ reaction with plasmalogen are other important markers of the RHS-induced lipid damage (Fig. 3). These compounds are less stable but can be detected in very low concentrations by mass spectrometry. 2-Chlorhexadecanal was found to accumulate in the rat heart during experimental myocardial infarction [184]. More than a 1400fold increase in the 2-chlorohexadecanal content was detected in the atherosclerotic plaques of human aorta compared with the aorta of healthy donors [91]. 2-Chloraldehyde and lysophosphatidylcholine are formed as result of the plasmalogen double bond break (Fig. 3). The 20 - and 34-fold increase in the content of lysophosphatidylcholine with arachidonic and linoleic acids, respectively, was observed in the atherosclerotic plaques compared with the non-diseased aorta [91].

Halogen derivatives of purine and pyrimidine bases can play the role of markers of the MPO-dependent degradation of nucleotides and nucleic acids. Thus, a 10fold increase in the level of 5-chlorouracil, which is formed in the body by the MPO-dependent mechanism, was found in the atherosclerosis-damaged areas of human aorta [185]. The amount of 5-bromouracil was higher in the atherosclerotic plaques compared with the unaffected areas of the aorta, but this difference was statistically insignificant [185].
Recently, we obtained specific antibodies against halogenated LDLs (LDL-Cl and LDL-Br) and chlorinated $\mathrm{CP}(\mathrm{CP}-\mathrm{Cl})[186,187]$. Using these antibodies, we were able to detect LDL-Cl, LDL-Br, as well as CP-Cl in the blood of CVD patients by an improved ELISA method. Interestingly, the content of LDL-Cl, LDL-Br, and $\mathrm{CP}-\mathrm{Cl}$ in the patients' blood correlated with the MPO level registered by ELISA and with the MPO halogenating activity $(r \sim 0.80)$. A high value of positive correlation was found for LDL-Cl and LDL- $\mathrm{Br}(r=0.91$; $p<0.0001$ ), although they were not associated with the peroxidase activities of either plasma or MPO [186]. These results confirm an important role of halogenative stress in the atherogenic modification of LDLs. Halogenated LDLs and CP can be used as potential biomarkers of halogenative stress in CVD.

The results presented in this review demonstrate an important role of halogenative stress in atherogenic modification of LDLs. The key element of the LDL modification is the site-specific binding of MPO to the LDL surface. Inhibition of MPO or dissociation of the MPO-LDL complex prevents MPO-dependent modification of LDLs, accumulation of cholesterol in the vascular cells, and early stages of atherosclerosis development. It has become obvious that one of the most important tasks in preventing and slowing down atherosclerosis is the development of tools and approaches for reduction of the MPO-dependent production of RHS. There are at least three different approaches. The first one is searching for methods that would limit the release of MPO during activation and degranulation of neutrophils. For example, this effect was found for the glucocorticoids $\alpha$-methylprednisolone and hydrocortisone [188]. The second approach is inhibition of the MPO halogenating activity, e.g., by MPO inhibition with CP [163, 164] or switching the enzyme to the peroxidase cycle by changing the medium [189]. The third approach is scavenging and neutralization of already formed RHS. Another possibility to prevent or to slow down atherosclerosis is the use of efficient, non-toxic components capable of disrupting the MPO-LDL complex, like the ${ }^{445}$ EQIQDDCTGDED ${ }^{456}$ peptide that mimics the MPO-binding site of ApoB100 on the LDL surface. Identification of new specific, sensitive, and informative biomarkers of MPO activity and halogenative stress is of particular importance, since it can provide the information for the development of modern methods for early diagnostics of atherosclerosis and CVDs. Further clarification of issues discussed in our review will allow to develop fundamentally new approaches aimed at identification and timely prevention of halogenative stress, and hence, atherosclerosis.

Funding. The authors' studies cited in this review were supported by the Russian Foundation for Basic 
Research (projects 17-04-00530 and 18-515-00004) and

Russian Science Foundation (project 17-75-30064).

Conflict of interest. The authors declare that there is no conflict of interest.

Compliance with ethical standards. This article does not contain any studies involving animals or human participants performed by any of the authors.

\section{REFERENCES}

1. Klimov, A. N., and Nikulicheva, N. G. (1999) Lipids and Lipoproteins Metabolism and Its Defects [in Russian], Piter, St. Petersburg.

2. Anichkov, N. N. (1965) Basic Theoretical Principles for Further Studies of the Problem of Atherosclerosis. Atherosclerosis [in Russian], Meditsina, Leningrad, pp. 1421.

3. Gofman, J. W., Glazier, F., Tamplin, A., Strisower, B., and De Lalla, O. (1954) Lipoproteins, coronary heart disease, and atherosclerosis, Physiol. Rev., 34, 589-607.

4. De Lalla, O. F., and Gofman, J. W. (1954) Ultracentrifugal analysis of serum lipoproteins, Methods Biochem. Anal., 1, 459-478

5. Tada, H., Kawashiri, M. A., Nohara, A., Inazu, A., Mabuchi, H., and Yamagishi, M. (2017) Impact of clinical signs and genetic diagnosis of familial hypercholesterolemia on the prevalence of coronary artery disease in patients with severe hypercholesterolemia, Eur. Heart J., 38, 1573-1579.

6. Carew, T. E. (1989) Role of biologically modified low-density lipoprotein in atherosclerosis, Am. J. Cardiol., 64, 18G22G.

7. Aviram, M. (1993) Modified forms of low-density lipoprotein and atherosclerosis, Atherosclerosis, 98, 1-9.

8. Brown, M. S., and Goldstein, J. L. (1976) Receptor-mediated control of cholesterol metabolism, Science, 191, 150154.

9. Goldstein, J. L., Ho, Y. K., Basu, S. K., and Brown, M. S. (1979) Binding site on macrophages that mediates uptake and degradation of acetylated low-density lipoprotein, producing massive cholesterol deposition, Proc. Natl. Acad. Sci. USA, 76, 333-337.

10. Fogelman, A. M., Schechter, J. S., Hokom, M. Child, J. S., and Edwards, P. A. (1980) Malondialdehyde alteration of low-density lipoprotein leads to cholesterol accumulation in human monocyte-macrophages, Proc. Natl. Acad. Sci. USA, 77, 2214-2218.

11. Panasenko, O. M., Azizova, O. A., and Vladimirov, Yu. A. (1992) Peroxidation of blood lipoproteins and development of atherosclerosis, Sov. Med. Rev. B. Physicochem. Asp. Med., 3, 1-74.

12. Steinbrecher, U. P., Zhang, H., and Lougheed, M. (1990) Role of oxidatively modified LDL in atherosclerosis, Free Radic. Biol. Med., 9, 155-168.

13. Panasenko, O. M., Aksenov, D. V., Mel'nichenko, A. A., Suprun, I. V., Yanushevskaya, E. V., Vlasik, T. N., Sobenin, I. A., and Orekhov, A. N. (2005) Proteolysis of apoprotein B-100 impairs its topography on LDL surface and reduces LDL association resistance, Bull. Exp. Biol. Med., 140, 521-525.
14. Piha, M., Lindstedt, L., and Kovanen, P. T. (1995) Fusion of proteolyzed low-density lipoprotein in the fluid phase: a novel mechanism generating atherogenic lipoprotein particles, Biochemistry, 34, 10120-10129.

15. Aksenov, D. V., Mel'nichenko, A. A., Suprun, I. V., Yanushevskaya, E. V., Vlasik, T. N., Sobenin, I. A., Panasenko, O. M., and Orekhov, A. N. (2005) Phospholipid hydrolysis with phospholipases A2 and C impairs apolipoprotein B-100 conformation on the surface of low density lipoproteins by reducing their association resistance, Bull. Exp. Biol. Med., 140, 419-422.

16. Mel'nichenko, A. A., Tertov, V. V., Ivanova, O. A., Aksenov, D. V., Sobenin, I. A., Popov, E. V., Kaplun, V. V., Suprun, I. V., Panasenko, O. M., and Orekhov, A. N. (2005) Desialylation decreases the resistance of apoB-containing lipoproteins to aggregation and increases their atherogenic potential, Bull. Exp. Biol. Med., 140, 51-54.

17. Panasenko, O. M., Tertov, V. V., Melnichenko, A. A., Aksenov, D. V., Sobenin, I. A., Kaplun, V. V., Suprun, I. V., and Orekhov, A. N. (2006) Correlation between the atherogenic potential and particle size of apoB-containing lipoproteins deglycosylated with different enzymes, Biol. Membr. (Moscow), 23, 225-234.

18. Turk, Z., and Skrabalo, Z. (1987) The cell-interactive properties of glucosylated very-low-density and low-density lipoproteins, Cell Mol. Biol., 33, 345-354.

19. Avogaro, P., Bon, G. B., and Cazzolato, G. (1988) Presence of a modified low-density lipoprotein in humans, Arteriosclerosis, 8, 79-87.

20. Tertov, V. V., Sobenin, I. A., Gabbasov, Z. A., Popov, E. G., Jaakkola, O., Solakivi, T., Nikkari, T., Smirnov, V. N., and Orekhov, A. N. (1992) Multiple-modified desialylated low density lipoproteins that cause intracellular lipid accumulation. Isolation, fractionation and characterization, Labor. Invest., 67, 665-675.

21. Austin, M. A., Breslow, J. L., Hennekens, C. H., Buring, J. E., Willett, W. C., and Krauss, R. M. (1988) Low-density lipoprotein subclass patterns and risk of myocardial infarction, JAMA, 260, 1917-1921.

22. Daugherty, A., Dunn, J. L., Rateri, D. L., and Heinecke, J. W. (1994) Myeloperoxidase, a catalyst for lipoprotein oxidation, is expressed in human atherosclerotic lesions, $J$. Clin. Invest., 94, 437-444.

23. Schindhelm, R. K., van der Zwan, L. P., Teerlink, T., and Scheffer, P. G. (2009) Myeloperoxidase: a useful biomarker for cardiovascular disease risk stratification? Clin. Chem., 55, 1462-1470.

24. Klebanoff, S. J. (2005) Myeloperoxidase: friend and foe, $J$. Leukoc. Biol., 77, 598-625.

25. Panasenko, O. M., Gorudko, I. V., and Sokolov, A. V. (2013) Hypochlorous acid as a precursor of free radicals in living systems, Biochemistry (Moscow), 78, 1466-1489.

26. Panasenko, O. M., and Sergienko, V. I. (2010) Halogenative stress and its biomarkers, Vestn. Ross. Akad. Med. Nauk, No. 1, 22-39.

27. Sies, H. (1991) Role of reactive oxygen species in biological processes, Klin. Wochenschr., 69, 965-968.

28. Darley-Usmar, V., and Halliwell, B. (1996) Blood radicals: reactive nitrogen species, reactive oxygen species, transition metal ions, and the vascular system, Pharm. Res., 13, 649-662.

29. Fiedler, T. J., Davey, C. A., and Fenna, R. E. (2000) X-ray crystal structure and characterization of halide-binding 
sites of human myeloperoxidase at $1.8 \AA$ resolution, J. Biol. Chem., 275, 11964-11971.

30. Schultz, J., and Kaminker, K. (1962) Myeloperoxidase of the leucocyte of normal human blood. 1. Content and localization, Arch. Biochem. Biophys., 96, 465-467.

31. Edwards, S. W. (1994) Biochemistry and Physiology of the Neutrophil, Cambridge University Press, Cambridge-New York-Melbourn, p. 299.

32. Deby-Dupont, G., Deby, C., and Lamy, M. (1999). Neutrophil myeloperoxidase revisited: its role in health and disease, Intensivmed, 36, 500-513.

33. Smith, R. J., Speziale, S. C., and Bowman, B. J. (1985) Properties of interleukin-1 as a complete secretogen for human neutrophils, Biochem. Biophys. Res. Commun., 130, 1233-1240.

34. Brinkmann, V., Reichard, U., Goosmann, C., Fauler, B., Uhlemann, Y., Weiss, D. S., Weinrauch, Y., and Zychlinsky, A. (2004) Neutrophil extracellular traps kill bacteria, Science, 303, 1532-1535.

35. Lau, D., Mollnau, H., Eiserich, J. P., Freeman, B. A., Daiber, A., Gehling, U. M., Brummer, J., Rudolph, V., Munzel, T., Heitzer, T., Meinertz, T., and Baldus, S. (2005) Myeloperoxidase mediates neutrophil activation by association with CD11b/CD18 integrins, Proc. Natl. Acad. Sci. USA, 102, 431-436.

36. Grigorieva, D. V., Gorudko, I. V., Sokolov, A. V., Kostevich, V. A., Vasilyev, V. B., Cherenkevich, S. N., and Panasenko, O. M. (2016) Myeloperoxidase stimulates neutrophil degranulation, Bull. Exp. Biol. Med., 161, 495-500.

37. Gorudko, I. V., Grigorieva, D. V., Sokolov, A. V., Shamova, E. V., Kostevich, V. A., Kudryavtsev, I. V., Syromiatnikova, E. D., Vasilyev, V. B., Cherenkevich, S. N., and Panasenko, O. M. (2018) Neutrophil activation in response to monomeric myeloperoxidase, Biochem. Cell Biol., 96, 592-601.

38. El Kebir, D., Jozsef, L., Pan, W., and Filep, J. G. (2008) Myeloperoxidase delays neutrophil apoptosis through CD11b/CD18 integrins and prolongs inflammation, Circ. Res., 103, 352-359.

39. Morris, J. C. (1966) The acid ionization constant of $\mathrm{HOCl}$ from 5 to $35^{\circ}$, J. Phys. Chem., 70, 3798-3805.

40. Furtmuller, P. G., Burner, U., and Obinger, C. (1998) Reaction of myeloperoxidase compound I with chloride, bromide, iodide, and thiocyanate, Biochemistry, 37, 1792317930.

41. Pattison, D. I., and Davies, M. J. (2006) Reactions of myeloperoxidase-derived oxidants with biological substrates: gaining chemical insight into human inflammatory diseases, Curr. Med. Chem., 13, 3271-3290.

42. Panasenko, O. M., Briviba, K., Klotz, L.-O., and Sies, H. (1997) Oxidative modification and nitration of human lowdensity lipoproteins by the reaction of hypochlorous acid with nitrite, Arch. Biochem. Biophys, 343, 254-259.

43. Eiserich, J. P., Cross, C. E., Jones, A. D., Halliwell, B., and van der Vliet, A. (1996) Formation of nitrating and chlorinating species by reaction of nitrite with hypochlorous acid. A novel mechanism for nitric oxide-mediated protein modification, J. Biol. Chem., 271, 19199-19208.

44. Byun, J., Mueller, M., Fabjan, J. S., and Heinecke, J. W. (1999) Nitrogen dioxide radical generated by the myeloperoxidase-hydrogen peroxide-nitrite system promotes lipid peroxidation of low density lipoproteins, FEBS Lett., 455, 243-246.
45. Furtmuller, P. G., Jantschko, W., Zederbauer, M., Jakopitsch, C., Arnhold, J., and Obinger, C. (2004) Kinetics of interconversion of redox intermediates of lactoperoxidase, eosinophil peroxidase and myeloperoxidase, Jpn. J. Infect. Dis., 57, S30-S31.

46. Kulinsky, V. I. (1999) Reactive oxygen forms and oxidative modification of macromolecules: benefit, harm and defense, Soros Educ. J., 1, 2-7.

47. Halliwell, B., and Gutteridge, J. M. C. (1999) Free Radical in Biology and Medicine, Oxford University Press, Oxford, pp. 617-783.

48. Gaut, J. P., Yeh, G. C., Tran, H. D., Byun, J., Henderson, J. P., Richter, G. M., Brennan, M. L., Lusis, A. J., Belaaouaj, A., Hotchkiss, R. S., and Heinecke, J. W. (2001) Neutrophils employ the myeloperoxidase system to generate antimicrobial brominating and chlorinating oxidants during sepsis, Proc. Natl. Acad. Sci. USA, 98, 1196111966.

49. Dunford, H. B., and Marquez-Curtis, L. A. (2002) Myeloperoxidase: kinetic evidence for formation of enzyme-bound chlorinating intermediate, Methods Enzymol., 354, 338-350.

50. Thukkani, A. K., Albert, C. J., Wildsmith, K. R., Messner, M. C., Martinson, B. D., Hsu, F. F., and Ford, D. A. (2003) Myeloperoxidase-derived reactive chlorinating species from human monocytes target plasmalogens in low density lipoprotein, J. Biol. Chem., 278, 36365-36372.

51. Albert, C. J., Crowley, J. R., Hsu, F. F., Thukkani, A. K., and Ford, D. A. (2002) Reactive brominating species produced by myeloperoxidase target the vinyl ether bond of plasmalogens: disparate utilization of sodium halides in the production of alpha-halo fatty aldehydes, J. Biol. Chem., 277, 4694-4703.

52. Panasenko, O. M., Gorudko, I. V., Kovaleva, A. M., Gusev, S. A., Sergienko, V. I., and Matishev, D. G. (2010) Production and properties of reactive halogen species in carcinogenesis, Vestnik Uzhn. Nauch. Tsentra RAN, 6, 7390.

53. Rudiger, J., Bobrowski, N., Liotta, M., and Hoffmann, T. (2017) Development and application of a sampling method for the determination of reactive halogen species in volcanic gas emissions, Anal. Bioanal. Chem., 409, 5975-5985.

54. Ronsein, G. E., Winterbourn, C. C., Di Mascio, P., and Kettle, A. J. (2014) Cross-linking methionine and amine residues with reactive halogen species, Free Radic. Biol. Med., 70, 278-287.

55. Pattison, D. I., and Davies, M. J. (2001) Absolute rate constants for the reaction of hypochlorous acid with protein side chains and peptide bonds, Chem. Res. Toxicol., 14, 1453-1464.

56. Pattison, D. I., and Davies, M. J. (2004) Kinetic analysis of the reactions of hypobromous acid with protein components: implications for cellular damage and use of 3-bromotyrosine as a marker of oxidative stress, Biochemistry, 43, 4799-4809.

57. Malle, E., Marsche, G., Arnhold, J., and Davies, M. J. (2006) Modification of low-density lipoprotein by myeloperoxidase-derived oxidants and reagent hypochlorous acid, Biochim. Biophys. Acta, 1761, 392-415.

58. Pattison, D. I., Hawkins, C. L., and Davies, M. J. (2003) Hypochlorous acid-mediated oxidation of lipid components and antioxidants present in low-density lipoproteins: 
absolute rate constants, product analysis, and computational modeling, Chem. Res. Toxicol., 16, 439-449.

59. Skaff, O., Pattison, D. I., and Davies, M. J. (2007) Kinetics of hypobromous acid-mediated oxidation of lipid components and antioxidants, Chem. Res. Toxicol., 20, 1980-1988.

60. Hazell, L. J., van den Berg, J. J., and Stocker, R. (1994) Oxidation of low-density lipoprotein by hypochlorite causes aggregation that is mediated by modification of lysine residues rather than lipid oxidation, Biochem. J., 302, 297-304.

61. Jerlich, A., Horakova, L., Fabjan, J. S., Giessauf, A., Jurgens, G., and Schaur, R. J. (1999) Correlation of lowdensity lipoprotein modification by myeloperoxidase with hypochlorous acid formation, Int. J. Clin. Lab. Res., 29, 155-161.

62. Yang, C. Y., Gu, Z. W., Yang, M., Lin, S. N., Garcia-Prats, A. J., Rogers, L. K., Welty, S. E., and Smith, C. V. (1999) Selective modification of ApoB100 in the oxidation of low density lipoproteins by myeloperoxidase in vitro, J. Lipid Res., 40, 686-698.

63. Delporte, C., Boudjeltia, K. Z., Noyon, C., Furtmuller, P. G., Nuyens, V., Slomianny, M. C., Madhoun, P., Desmet, J. M., Raynal, P., Dufour, D., Koyani, C. N., Reye, F., Rousseau, A., Vanhaeverbeek, M., Ducobu, J., Michalski, J. C., Neve, J., Vanhamme, L., Obinger, C., Malle, E., and Van Antwerpen, P. (2014) Impact of myeloperoxidaseLDL interactions on enzyme activity and subsequent posttranslational oxidative modifications of ApoB100, J. Lipid Res., 55, 747-757.

64. Hawkins, C. L., and Davies, M. J. (2005) The role of reactive $\mathrm{N}$-bromo species and radical intermediates in hypobromous acid-induced protein oxidation, Free Radic. Biol. Med., 9, 900-912.

65. Hawkins, C. L., Pattison, D. I., and Davies, M. J. (2003) Hypochlorite-induced oxidation of amino acids, peptides and proteins, Amino Acids, 25, 259-274.

66. Fu, X., Mueller, D. M., and Heinecke, J. W. (2002) Generation of intramolecular and intermolecular sulfenamides, sulfinamides, and sulfonamides by hypochlorous acid: a potential pathway for oxidative cross-linking of lowdensity lipoprotein by myeloperoxidase, Biochemistry, 41, 1293-1301.

67. Heinecke, J. W., Li, W., Francis, G. A., and Goldstein, J. A. (1993) Tyrosyl radical generated by myeloperoxidase catalyzes the oxidative cross-linking of proteins, J. Clin. Invest., 91, 2866-2872.

68. Thomas, E. L. (1979) Myeloperoxidase, hydrogen peroxide, chloride antimicrobial system: nitrogen-chlorine derivatives of bacterial components in bactericidal action against Escherichia coli, Infect. Immun., 23, 522-531.

69. Hawkins, C. L., and Davies, M. J. (1998) Reaction of $\mathrm{HOCl}$ with amino acids and peptides: EPR evidence for rapid rearrangement and fragmentation reactions of nitrogencentered radicals. J. Chem. Soc. Perkin Trans., 2, 1937-1945.

70. Podrez, E. A., Febbraio, M., Sheibani, N., Schmitt, D., Silverstein, R. L., Hajjar, D. P., Cohen, P. A., Frazier, W. A., Hoff, H. F., and Hazen, S. L. (2000) Macrophage scavenger receptor CD36 is the major receptor for LDL modified by monocyte-generated reactive nitrogen species, $J$. Clin. Invest., 105, 1095-1108.

71. Panasenko, O. M., Arnhold, J., and Sergienko, V. I. (2002) Impairment of membrane lipids by hypochlorite, Biol. Membr. (Moscow), 19, 403-434.
72. Panasenko, O. M., Arnhold, J., Sergienko, V. I., Arnold, K., and Vladimirov, Yu. A. (1996) Stoichiometry of hypochlorite interaction with unsaturated bonds of phosphatidylcholine and free fatty acids in liposomes, Membr. Cell Biol., 10, 291-302.

73. Winterbourn, C. C., van den Berg, J. J., Roitman, E., and Kuypers, F. A. (1992) Chlorohydrin formation from unsaturated fatty acids reacted with hypochlorous acid, Arch. Biochem. Biophys., 296, 547-555.

74. Spalteholz, H., Panasenko, O. M., and Arnhold, J. (2006) Formation of reactive halide species by myeloperoxidase and eosinophil peroxidase, Arch. Biochem. Biophys., 445, 225-234.

75. Panasenko, O. M., Vakhrusheva, T., Tretyakov, V., Spalteholz, H., and Arnhold, J. (2007) Influence of chloride on modification of unsaturated phosphatidylcholines by the myeloperoxidase/hydrogen peroxide/bromide system, Chem. Phys. Lipids, 149, 40-51.

76. Carr, A. C., Winterbourn, C. C., and van den Berg, J. J. (1996) Peroxidase-mediated bromination of unsaturated fatty acids to form bromohydrins, Arch. Biochem. Biophys., 327, 227-233.

77. Panasenko, O. M., Spalteholz, H., Schiller, J., and Arnhold, J. (2006) Leukocytic myeloperoxidase-mediated formation of bromohydrins and lysophospholipids from unsaturated phosphatidylcholines, Biochemistry (Moscow), 71, 571-580.

78. Panasenko, O. M., Osipov, A. N., Schiller, J., and Arnhold, J. (2002) Interaction of exogenous hypochlorite or hypochlorite produced by myeloperoxidase $+\mathrm{H}_{2} \mathrm{O}_{2}+\mathrm{Cl}^{-}$ system with unsaturated phosphatidylcholines, Biochemistry (Moscow), 67, 889-900.

79. Panasenko, O. M., Spalteholz, H., Schiller, J., and Arnhold, J. (2003). Myeloperoxidase-induced formation of chlorohydrins and lysophospholipids from unsaturated phosphatidylcholines, Free Radic. Biol. Med., 34, 553-562.

80. Panasenko, O. M., Spalteholz, H., Schiller, J., and Arnhold, J. (2004) Myeloperoxidase mediated destruction of unsaturated phosphatidylcholines in liposomes, Biol. Membr. (Moscow), 21, 138-150.

81. Spalteholz, H., Wenske, K., Panasenko, O. M., Schiller, J., and Arnhold, J. (2004) Evaluation of products upon the reaction of hypochlorous acid with unsaturated phosphatidylcholines, Chem. Phys. Lipids, 129, 85-96.

82. Arnhold, J., Osipov, A. N., Spalteholz, H., Panasenko, O. M., and Schiller, J. (2002) Formation of lysophospholipids from unsaturated phosphatidylcholines under the influence of hypochlorous acid, Biochim. Biophys. Acta, 1572, 91100.

83. Arnhold, J., Osipov, A. N., Spalteholz, H., Panasenko, O. M., and Schiller, J. (2001) Effects of hypochlorous acid on unsaturated phosphatidylcholines, Free Radic. Biol. Med., 31, 1111-1119.

84. Engelmann, B., Brautigam, C., and Thiery, J. (1994) Plasmalogen phospholipids as potential protectors against lipid peroxidation of low density lipoproteins, Biochem. Biophys. Res. Commun., 204, 1235-1242.

85. Albert, C. J., Crowley, J. R., Hsu, F. F., Thukkani, A. K., and Ford, D. A. (2001) Reactive chlorinating species produced by myeloperoxidase target the vinyl ether bond of plasmalogens. Identification of 2-chlorohexadecanal, $J$. Biol. Chem., 276, 23733-23741. 
86. Leßig, J., Schiller, J., Arnhold, J., and Fuchs, B. (2007) Hypochlorous acid-mediated generation of glycerophosphocholine from unsaturated plasmalogen glycerophosphocholine lipids, J. Lipid Res., 48, 1316-1324.

87. Messner, M. C., Albert, C. J., Hsu, F., and Ford, D. A. (2006) Selective plasmenylcholine oxidation by hypochlorous acid: formation of lysophosphatidylcholine chlorohydrins, Chem. Phys. Lipids, 144, 34-44.

88. Skaff, O., Pattison, D. I., and Davies, M. J. (2008) The vinyl ether linkages of plasmalogens are favored targets for myeloperoxidase-derived oxidants: a kinetic study, Biochemistry, 47, 8237-8245.

89. Schiller, J., Zschornig, O., Petkovic, M., Muller, M., Arnhold, J., and Arnold, K. (2001) Lipid analysis of human HDL and LDL by MALDI-TOF mass spectrometry and ${ }^{31}$ P-NMR, J. Lipid Res., 42, 1501-1508.

90. Zakiev, E. R., Sukhorukov, V. N., Melnichenko, A. A., Sobenin, I. A., Ivanova, E. A., and Orekhov, A. N. (2016) Lipid composition of circulating multiple-modified lowdensity lipoprotein, Lipids Health Dis., 15, 134.

91. Thukkani, A. K., McHowat, J., Hsu, F. F., Brennan, M. L., Hazen, S. L., and Ford, D. A. (2003) Identification of alpha-chloro fatty aldehydes and unsaturated lysophosphatidylcholine molecular species in human atherosclerotic lesions, Circulation, 108, 3128-3133.

92. Siess, W., Zangl, K. J., Essler, M., Bauer, M., Brandl, R., Corrinth, C., Bittman, R., Tigyi, G., and Aepfelbacher, M. (1999) Lysophosphatidic acid mediates the rapid activation of platelets and endothelial cells by mildly oxidized low density lipoprotein and accumulates in human atherosclerotic lesions, Proc. Nat. Acad. Sci. USA, 96, 6931-6936.

93. Nusshold, C., Kollroser, M., Kofeler, H., Rechberger, G., Reicher, H., Ullen, A., Bernhart, E., Waltl, S., Kratzer, I., Hermetter, A., Hackl, H., Trajanoski, Z., Hrzenjak, A., Malle, E., and Sattler, W. (2010) Hypochlorite modification of sphingomyelin generates chlorinated lipid species that induce apoptosis and proteome alterations in dopaminergic PC12 neurons in vitro, Free Radic. Biol. Med., 48, 1588-600.

94. Spalteholz, H., Wenske, K., and Arnhold, J. (2005) Interaction of hypohalous acids and heme peroxidases with unsaturated phosphatidylcholines, Biofactors, 24, 67-76.

95. Heinecke, J. W., Li, W., Mueller, D. M., Bohrer, A., and Turk, J. (1994) Cholesterol chlorohydrin synthesis by the myeloperoxidase-hydrogen peroxide-chloride system: potential markers for lipoproteins oxidatively damaged by phagocytes, Biochemistry, 33, 10127-10136.

96. Carr, A. C., van den Berg, J. J., and Winterbourn, C. C. (1996) Chlorination of cholesterol in cell membranes by hypochlorous acid, Arch. Biochem. Biophys., 332, 63-69.

97. Hazen, S. L., Hsu, F. F., Duffin, K., and Heinecke, J. W. (1996) Molecular chlorine generated by the myeloperoxidase-hydrogen peroxide-chloride system of phagocytes converts low density lipoprotein cholesterol into a family of chlorinated sterols, J. Biol. Chem., 271, 23080-23088.

98. Van den Berg, J. J., Winterbourn, C. C., and Kuypers, F. A. (1993) Hypochlorous acid-mediated modification of cholesterol and phospholipid: analysis of reaction products by gas chromatography-mass spectrometry, J. Lipid Res., 34, 2005-2012.

99. Sergienko, V. I., Panasenko, O. M., and Murina, M. A. (1999) Development and introduction of electrochemical methods of detoxication in medicine, Efferent. Ter., 5, No. 4, 8-17.
100. Vissers, M. C., Carr, A. C., and Chapman, A. L. (1998) Comparison of human red cell lysis by hypochlorous and hypobromous acids: insights into the mechanism of lysis, Biochem. J., 330, 131-138.

101. Panasenko, O. M. (1997). The mechanism of the hypochlorite-induced lipid peroxidation, Biofactors, 6, 181-190.

102. Stelmaszynska, T., Kukovetz, E., Egger, G., and Schaur, R. J. (1992) Possible involvement of myeloperoxidase in lipid peroxidation, Int. J. Biochem., 24, 121-128.

103. Evgina, S. A., Panasenko, O. M., Sergienko, V. I., and Vladimirov, Yu. A. (1992) Peroxidation of human plasma lipoproteins induced by hypochlorite, Biol. Membr. (Moscow), 6, 1247-1254.

104. Hazell, L. J., Davies, M. J., and Stocker, R. (1999) Secondary radicals derived from chloramines of apolipoprotein B-100 contribute to $\mathrm{HOCl}$-induced lipid peroxidation of low-density lipoproteins, Biochem. J., 339, 489-495.

105. Panasenko, O. M., Evgina, S. A., Aidyraliev, R. K., Sergienko, V. I., and Vladimirov, Yu. A. (1994) Peroxidation of human blood lipoproteins induced by exogenous hypochlorite or hypochlorite generated in the system of "myeloperoxidase $+\mathrm{H}_{2} \mathrm{O}_{2}+\mathrm{Cl}^{-}$", Free Radic. Biol. Med., 16, 143-148.

106. Panasenko, O. M., Evgina, S. A., Driomina, E. S., Sharov, V. S., Sergienko, V. I., and Vladimirov, Yu. A. (1995) Hypochlorite induces lipid peroxidation in blood lipoproteins and phospholipid liposomes, Free Radic. Biol. Med., 19, 133-140.

107. Panasenko, O. M., Arnhold, J., Arnhold, K., Vladimirov, Iu. A., and Sergienko, V. I. (1996) Comparative study of the kinetics of phospholipid liposome peroxidation, induced by hypochlorite and in the $\mathrm{Fe}^{2+}+$ ascorbate system, Biofizika, 41, 334-341.

108. Gorbatenkova, E. A., Artmann, G. M., and Panasenko, O. M. (2000) Hypochlorous acid and human blood low density lipoproteins modified by hypochlorous acid increase erythrocyte adhesion to endothelial cells, Membr. Cell Biol., 13, 537-546.

109. Panasenko, O. M., Evgina, S. A., and Sergienko, V. I. (1993) Capacity of hypochlorite to penetrate into the lipid phase of human blood lipoproteins, Bull. Exp. Biol. Med., 115, 358-360.

110. Panasenko, O. M., Panasenko, O. O., Briviba, K., and Sies, H. (1997) Hypochlorite destroys carotenoids in low density lipoproteins thus decreasing their resistance to peroxidative modification, Biochemistry (Moscow), 62, 11401145.

111. Chekanov, A. V., Osipov, A. N., Vladimirov, Iu. A., Sergienko, V. I., and Panasenko, O. M. (2007) A comparative spin trapping study of hypobromous and hypochlorous acids interaction with tert-butyl hydroperoxide, Biofizika, 52, 5-13.

112. Rice-Evans, C., Leake, D., Bruckdorfer, K. R., and Diplock, A. T. (1996) Practical approaches to low density lipoprotein oxidation: whys, wherefores and pitfalls, Free Radic. Res., 25, 285-311.

113. Osipov, A. N., Panasenko, O. M., Chekanov, A. V., and Arnhold, J. (2002) Interaction of tert-butyl hydroperoxide with hypochlorous acid. A spin trapping and chemiluminescence study, Free Radic. Res., 36, 749-754. 
114. Panasenko, O. M., Osipov, A. N., Chekanov, A. V., Arnhold, J., and Sergienko, V. I. (2002) Peroxyl radical is produced upon the interaction of hypochlorite with tertbutyl hydroperoxide, Biochemistry (Moscow), 67, 880-888.

115. Chekanov, A. V., Panasenko, O. M., Osipov, A. N., Arnhold, J., Kazarinov, K. D., Vladimirov, Iu. A., and Sergienko, V. I. (2002) Interaction of tert-butyl hydroperoxide with hypochlorite induces peroxyl radicals. A chemiluminescence study, Biofizika, 47, 787-794.

116. Chekanov, A. V., Panasenko, O. M., Osipov, A. N., Matveeva, N. S., Kazarinov, K. D., Vladimirov, Iu. A., and Sergienko, V. I. (2005) The interaction of hypochlorite with fatty acid hydroperoxides results in the generation of free radicals, Biofizika, 50, 13-19.

117. Panasenko, O. M., Chekanov, A. V., Arnhold, J., Sergienko, V. I., Osipov, A. N., and Vladimirov, Y. A. (2005) Generation of free radicals during decomposition of hydroperoxide in the presence of myeloperoxidase or activated neutrophils, Biochemistry (Moscow), 70, 9981004.

118. Chekanov, A. V., Osipov, A. N., Vladimirov, Yu. A., Sergienko, V. I., and Panasenko, O. M. (2006) Interaction of hypobromite with tert-butyl hydroperoxide. Role in phospholipid liposome peroxidation, Biol. Membr. (Moscow), 23, 426-432.

119. Noguchi, N., Nakada, A., Itoh, Y., Watanabe, A., and Niki, E. (2002) Formation of active oxygen species and lipid peroxidation induced by hypochlorite, Arch. Biochem. Biophys., 397, 440-447.

120. Miyamoto, S., Martinez, G. R., Rettori, D., Augusto, O., Medeiros, M. H. G., and Di Mascio, P. (2006) Linoleic acid hydroperoxide reacts with hypochlorous acid, generating peroxyl radical intermediates and singlet molecular oxygen, Proc. Natl. Acad. Sci. USA, 103, 293-298.

121. Crisby, M., Henareh, L., and Agewall, S. (2014) Relationship between oxidized LDL, IgM, and $\operatorname{IgG}$ autoantibodies to ox-LDL levels with recurrent cardiovascular events in Swedish patients with previous myocardial infarction, Angiology, 65, 932-936.

122. Holvoet, P., Vanhaecke, J., Janssens, S., Van de Werf, F., and Collen, D. (1998) Oxidized LDL and malondialdehyde-modified LDL in patients with acute coronary syndromes and stable coronary artery disease, Circulation, 98, 1487-1489.

123. Osipov, A. N., Briukhanova, E. V., Vakhrusheva, T. V., Panasenko, O. M., and Vladimirov, Iu. A. (1997) Effect of hypochlorite and hydrogen peroxide on the ability of hemoglobin to stimulate lipid peroxidation of low-density lipoproteins, Biofizika, 42, 400-407.

124. Yakutova, E. Sh., Dremina, Ye. S., Yevgina, S. A., Osipov, A. N., Sharov, V. S., Panasenko, O. M., and Vladimirov, Yu. A. (1994) Formation of free radicals on interaction of hypochlorite with iron (II) ions, Biophysics, 39, 241-245.

125. Savenkova, M. L., Mueller, D. M., and Heinecke, J. W. (1994) Tyrosyl radical generated by myeloperoxidase is a physiological catalyst for the initiation of lipid peroxidation in low density lipoprotein, J. Biol. Chem., 269, 20394-20400.

126. Kawai, Y., Kiyokawa, H., Kimura, Y., Kato, Y., Tsuchiya, K., and Terao, J. (2006) Hypochlorous acid-derived modification of phospholipids: characterization of aminophospholipids as regulatory molecules for lipid peroxidation, Biochemistry, 45, 14201-14211.
127. Arnhold, J., Panasenko, O. M., Schiller, J., Vladimirov, Yu. A., and Arnold, K. (1995) The action of hypochlorous acid on phosphatidylcholine liposomes in dependence on the content of double bonds. Stoichiometry and NMR analysis, Chem. Phys. Lipids, 78, 55-64.

128. Panasenko, O. M., Arnhold, J., Vladimirov, Yu. A., Arnold, K., and Sergienko, V. I. (1997) Hypochloriteinduced peroxidation of egg yolk phosphatidylcholine is mediated by hydroperoxides, Free Radic. Res., 27, 1-12.

129. Richter, G., Schober, C., Suß, R., Fuchs, B., Birkemeyer, C., and Schiller, J. (2008) Comparison of the positive and negative ion electrospray ionization and matrix-assisted laser desorption ionization-time-of-flight mass spectra of the reaction products of phosphatidylethanolamines and hypochlorous acid, Anal. Biochem., 376, 157-159.

130. Carr, A. C., van den Berg, J. J., and Winterbourn, C. C. (1998) Differential reactivities of hypochlorous and hypobromous acids with purified Escherichia coli phospholipid: formation of haloamines and halohydrins, Biochim. Biophys. Acta, 1392, 254-264.

131. Tertov, V. V., Orekhov, A. N., Sobenin, I. A., Morrisett, J. D., Gotto, A. M., and Guevara, J. G., (1993) Carbohydrate composition of protein and lipid components in sialic acid-rich and -poor low-density lipoproteins from subjects with and without coronary artery disease, $J$. Lipid Res., 34, 365-375.

132. Taniguchi, T., Ishikawa, Y., Tsunemitsu, M., and Fukuzaki, H. (1989) The structures of asparagine-linked sugar chains of human apolipoprotein B-100, Arch. Biochem. Biophys., 273, 197-205.

133. Prutz, W. A. (1996) Hypochlorous acid interactions with thiols, nucleotides, DNA, and other biological substrates, Arch. Biochem. Biophys., 332, 110-120.

134. Schiller, J., Arnhold, J., and Arnold, K. (1995) Action of hypochlorous acid on polymeric components of cartilage. Use of ${ }^{13} \mathrm{C}$ NMR spectroscopy, Z. Naturforsch., 50, 721-728.

135. Schiller, J., Arnhold, J., and Arnold, K. (1995) NMR studies of the action of hypochlorous acid on native pig articular cartilage, Eur. J. Biochem., 233, 672-676.

136. Hawkins, C. L., and Davies, M. J. (1998) Degradation of hyaluronic acid, poly- and monosaccharides, and model compounds by hypochlorite: evidence for radical intermediates and fragmentation, Free Radic. Biol. Med., 24, 1396-1410.

137. Rees, M. D., Hawkins, C. L., and Davies, M. J. (2003) Hypochlorite-mediated fragmentation of hyaluronan, chondroitin sulfates, and related $\mathrm{N}$-acetyl glycosamines: evidence for chloramide intermediates, free radical transfer reactions, and site-specific fragmentation, J. Am. Chem. Soc., 125, 13719-13733.

138. Rees, M. D., Mcniven, T. N., and Davies, M. J. (2007) Degradation of extracellular matrix and its components by hypobromous acid, Biochem. J., 401, 587-596.

139. Rees, M. D., Hawkins, C. L., and Davies, M. J. (2004) Hypochlorite and superoxide radicals can act synergistically to induce fragmentation of hyaluronan and chondroitin sulphates, Biochem. J., 381, 175-184.

140. Rees, M. D., and Davies, M. J. (2006) Heparan sulfate degradation via reductive homolysis of its N-chloro-derivatives, Am. Chem. Soc., 128, 3085-3097.

141. Tertov, V. V., Kaplun, V. V., Sobenin, I. A., and Orekhov, A. N. (1998) Low-density lipoprotein modification occurring 
in human plasma. Possible mechanism of in vivo lipoprotein desialylation as a primary step of atherogenic modification, Atherosclerosis, 138, 183-195.

142. Sukhorukov, V. N., Karagodin, V. P., and Orekhov, A. N. (2016) Atherogenic modification of low-density lipoproteins, Biomed. Khim., 62, 391-402.

143. Tertov, V. V., Nikonova, E. Y., Nifant'ev, N. E., Bovin, N. V., and Orekhov, A. N. (2002) Human plasma trans-sialidase donor and acceptor specificity, Biochemistry (Moscow), 67, 908-913.

144. Estrbauer, H., Puhl, H., Waeg, G., Krebs, A., Tatzber, F., and Rabol, H. (1993) Vitamin E and atherosclerosis - an overview, in Vitamin $E$ (Mino, M., Nakamura, H., Diplock, A. T., and Keyden, H. J., eds.) Japan Scientific Societies Press, Tokyo, pp. 233-241.

145. Hazell, L. J., and Stocker, R. (1993) Oxidation of lowdensity lipoprotein with hypochlorite causes transformation of the lipoprotein into a high-uptake form for macrophages, Biochem. J., 290, 165-172.

146. Albrich, J. M., McCarthy, C. A., and Hurst, J. K. (1981) Biological reactivity of hypochlorous acid: implications for microbicidal mechanisms of leukocyte myeloperoxidase, Proc. Natl. Acad. Sci. USA, 78, 210-214.

147. Hazell, L. J., and Stocker, R. (1997) $\alpha$-Tocopherol does not inhibit hypochlorite-induced oxidation of apolipoprotein B-100 of low-density lipoprotein, FEBS Lett., 414, 541-544.

148. Panasenko, O. M., Evgina, S. A., and Sergienko, V. I. (1993) A spin-probe study of the structural change in human blood lipoproteins under the action of sodium hypochlorite, Bull. Exp. Biol. Med., 116, 153-155.

149. Panasenko, O. M. (1998) Hypochlorite and Oxidative Modification of Human Blood Lipoproteins: Ph. D. Thesis, Biological Sciences [in Russian], Research Institute of Physico-Chemical Medicine, Moscow.

150. Panasenko, O. M., Borin, M. L., Azizova, O. A., and Arnol'd, K. (1985) Determination of the surface charge of lipoproteins and its changes during lipid peroxidation, Biofizika, 30, 822-827.

151. Panasenko, O. M., Evgina, S. A., Nikitin, S. V., and Sergienko, V. I. (1995) The effect of hypochlorite on electrical surface properties of human blood lipoproteins, Biofizika, 40, 545-550.

152. Jerlich, A., Fabjan, J. S., Tschabuschnig, S., Smirnova, A. V., Horakova, L., Hayn, M., Auer, H., Guttenberger, H., Leis, H. J., Tatzber, F., Waeg, G., and Schaur, R. J. (1998) Human low density lipoprotein as a target of hypochlorite generated by myeloperoxidase, Free Radic. Biol. Med., 24, 1139-1148.

153. Panasenko, O. M., Melnichenko, A. A., Aksenov, D. V., Vakhrusheva, T. V., Suprun, I. V., Yanushevskaya, E. V., Vlasik, T. N., Sobenin, I. A., and Orekhov, A. N. (2004) Myeloperoxidase increases atherogenic potential of human blood low density lipoproteins by modifying their surface and lowering the resistance to association, Biol. Membr. (Moscow), 21, 498-505.

154. Guyton, J. R., and Klemp, K. F. (1994) Development of the atherosclerotic core region. Chemical and ultrastructural analysis of microdissected atherosclerotic lesions from human aorta, Arterioscler. Thromb., 14, 1305-1314.

155. Tirziu, D., Dobrian, A., Tasca, C., Simionescu, M., and Simionescu, N. (1995) Intimal thickenings of human aorta contain modified reassembled lipoproteins, Atherosclerosis, 112, 101-114.

156. O'Connell, A. M., Gieseg, S. P., and Stanley, K. K. (1994) Hypochlorite oxidation causes cross-linking of Lp(a), Biochim. Biophys. Acta, 1225, 180-186.

157. Panasenko, O. M., Azizova, O. A., Arnold, K., and Borin, M. L. (1987) Alterations of surface charges of plasma lipoproteins in ischemic heart disease, Biomed. Biochim. Acta, 46, 97-102.

158. Carr, A. C., Myzak, M. C., Stocker, R., McCall, M. R., and Frei, B. (2000) Myeloperoxidase binds to low-density lipoprotein: potential implications for atherosclerosis, FEBS Lett., 487, 176-180.

159. Sokolov, A. V., Chekanov, A. V., Kostevich, V. A., Aksenov, D. V., Vasilyev, V. B., and Panasenko, O. M. (2011) Revealing binding sites for myeloperoxidase on the surface of human low density lipoproteins, Chem. Phys. Lipids, 164, 49-53.

160. Sokolov, A. V., Ageeva, K. V., Cherkalina, O. S., Pulina, M. O., Zakharova, E. T., Prozorovskii, V. N., Aksenov, D. V., Vasilyev, V. B., and Panasenko, O. M. (2010) Identification and properties of complexes formed by myeloperoxidase with lipoproteins and ceruloplasmin, Chem. Phys. Lipids, 163, 347-355.

161. Sokolov, A. V., Kostevich, V. A., Runova, O. L., Gorudko, I. V., Vasilyev, V. B., Cherenkevich, S. N., and Panasenko, O. M. (2014) Proatherogenic modification of LDL by surfacebound myeloperoxidase, Chem. Phys. Lipid, 180, 72-80.

162. Segelmark, M., Persson, B., Hellmark, T., and Wieslander, J. (1997) Binding and inhibition of myeloperoxidase (MPO): a major function of ceruloplasmin? Clin. Exp. Immunol., 108, 167-174.

163. Sokolov, A. V., Ageeva, K. V., Pulina, M. O., Cherkalina, O. S., Samygina, V. R., Vlasova, I. I., Panasenko, O. M., Zakharova, E. T., and Vasilyev, V. B. (2008) Ceruloplasmin and myeloperoxidase in complex affect the enzymatic properties of each other, Free Radic. Res., 42, 989-998.

164. Panasenko, O. M., Chekanov, A. V., Vlasova, I. I., Sokolov, A. V., Ageeva, K. V., Pulina, M. O., Cherkalina, O. S., and Vasil'ev, V. B. (2008) A study of the effect of ceruloplasmin and lactoferrin on the chlorination activity of leukocytic myeloperoxidase using the chemiluminescence method, Biophysics, 53, 268-272.

165. Karakas, M., and Koenig, W. (2012) Myeloperoxidase production by macrophage and risk of atherosclerosis, Curr. Atheroscler. Rep., 14, 277-283.

166. Zhang, R., Brennan, M. L., Fu, X., Aviles, R. J., Pearce, G. L., Penn, M. S., Topol, E. J., Sprecher, D. L., and Hazen, S. L. (2001) Association between myeloperoxidase levels and risk of coronary artery disease, JAMA, 286, 2136-2142.

167. Chen, L. Q., Rohatgi, A., Ayers, C. R., Das, S. R., Khera, A., Berry, J. D., McGuire, D. K., de and Lemos, J. A. (2011) Race-specific associations of myeloperoxidase with atherosclerosis in a population-based sample: the Dallas Heart Study, Atherosclerosis, 219, 833-838.

168. Karakas, M., Koenig, W., Zierer, A., Herder, C., Rottbauer, W., Baumert, J., Meisinger, C., and Thorand, B. (2012) Myeloperoxidase is associated with incident coronary heart disease independently of traditional risk factors: results from the MONICA/KORA Augsburg study, J. Intern. Med., 271, 43-50. 
169. Sugiyama, S., Okada, Y., Sukhova, G. K., Virmani, R., Heinecke, J. W., and Libby, P. (2001) Macrophage myeloperoxidase regulation by granulocyte macrophage colony-stimulating factor in human atherosclerosis and implications in acute coronary syndromes, Am. J. Pathol., 158, 879-891.

170. Cheng, M. L., Chen, C. M., Gu, P. W., Ho, H. Y., and Chiu, D. T. (2008) Elevated levels of myeloperoxidase, white blood cell count and 3-chlorotyrosine in Taiwanese patients with acute myocardial infarction, Clin. Biochem., 41, 554-560.

171. Ho, H. Y., Cheng, M. L., Chen, C. M., Gu, P. W., Wang,Y. L., Li, J. M., and Chiu, D. T. (2008) Oxidative damage markers and antioxidants in patients with acute myocardial infarction and their clinical significance, Biofactors, 34, 135-145.

172. Hazen, S. L., and Heinecke, J. W. (1997) 3Chlorotyrosine, a specific marker of myeloperoxidase-catalyzed oxidation, is markedly elevated in low density lipoprotein isolated from human atherosclerotic intima, $J$. Clin. Invest., 99, 2075-2081.

173. Hazen, S. L., Crowley, J. R., Mueller, D. M., and Heinecke, J. W. (1997) Mass spectrometric quantification of 3-chlorotyrosine in human tissues with attomole sensitivity: a sensitive and specific marker for myeloperoxidasecatalyzed chlorination at sites of inflammation, Free Radic. Biol. Med., 23, 909-916.

174. Bergt, C., Pennathur, S., Fu, X., Byun, J., O’Brien, K., McDonald, T. O., Singh, P., Anantharamaiah, G. M., Chait, A., Brunzell, J., Geary, R. L., Oram, J. F., and Heinecke, J. W. (2004) The myeloperoxidase product hypochlorous acid oxidizes HDL in the human artery wall and impairs ABCA1-dependent cholesterol transport, Proc. Natl. Acad. Sci. USA, 101, 13032-13037.

175. Pennathur, S., Bergt, C., Shao, B., Byun, J., Kassim, S. Y., Singh, P., Green, P. S., McDonald, T. O., Brunzell, J., Chait, A., Oram, J. F., O’brien, K., Geary, R. L., and Heinecke, J. W. (2004) Human atherosclerotic intima and blood of patients with established coronary artery disease contain high density lipoprotein damaged by reactive nitrogen species, J. Biol. Chem., 279, 42977-42983.

176. Zheng, L., Nukuna, B., Brennan, M. L., Sun, M., Goormastic, M., Settle, M., Schmitt, D., Fu, X., Thomson, L., Fox, P. L., Ischiropoulos, H., Smith, J. D., Kinter, M., and Hazen, S. L. (2004) Apolipoprotein A-I is a selective target for myeloperoxidase-catalyzed oxidation and functional impairment in subjects with cardiovascular disease, J. Clin. Invest., 114, 529-541.

177. Rudolph, V., Andrie, R. P., Rudolph, T. K., Friedrichs, K., Klinke, A., Hirsch-Hoffmann, B., Schwoerer, A. P., Lau, D., Fu, X., Klingel, K., Sydow, K., Didie, M., Seniuk, A., von Leitner, E. C., Szoecs, K., Schrickel, J. W., Treede, H., Wenzel, U., Lewalter, T., Nickenig, G., Zimmermann, W. H., Meinertz, T., Boger, R. H., Reichenspurner, H., Freeman, B. A., Eschenhagen, T., Ehmke, H., Hazen, S. L., Willems, S., and Baldus, S. (2010) Myeloperoxidase acts as a profibrotic mediator of atrial fibrillation, Nat. Med., 16, 470-474.
178. Malle, E., Hazell, L., Stocker, R., Sattler, W., Esterbauer, H., and Waeg, G. (1995) Immunologic detection and measurement of hypochlorite-modified LDL with specific monoclonal antibodies, Arterioscler. Thromb. Vasc. Biol., 15, 982-989.

179. Hazell, L. J., Arnold, L., Flowers, D., Waeg, G., Malle, E., and Stocker, R. (1996) Presence of hypochlorite-modified proteins in human atherosclerotic lesions, J. Clin. Invest., 97, 1535-1544.

180. Hazell, L. J., Baernthaler, G., and Stocker, R. (2001) Correlation between intima-to-media ratio, apolipoprotein B-100, myeloperoxidase, and hypochlorite-oxidized proteins in human atherosclerosis, Free Radic. Biol. Med., 31, 1254-1262.

181. Jerlich, A., Pitt, A. R., Schaur, R. J., and Spickett, C. M. (2000) Pathways of phospholipid oxidation by $\mathrm{HOCl}$ in human LDL detected by LC-MS, Free Radic. Biol. Med., 28, 673-682.

182. Messner, M. C., Albert, C. J., McHowat, J., and Ford, D. A. (2008) Identification of lysophosphatidylcholinechlorohydrin in human atherosclerotic lesions, Lipids, $\mathbf{4 3}$, 243-249.

183. Domigan, N. N., Carr, A. C., Lewis, J. G., Elder, P. A., and Winterbourn, C. C. (1997) A monoclonal antibody recognizing the chlorohydrin derivates of oleic acid for probing hypochlorous acid involvement in tissue injury, Redox Rep., 3, 111-117.

184. Thukkani, A. K., Martinson, B. D., Albert, C. J., Vogler, G. A., and Ford, D. A. (2005) Neutrophil-mediated accumulation of 2-ClHDA during myocardial infarction: 2ClHDA-mediated myocardial injury, Am. J. Physiol. Heart Circ. Physiol., 288, H2955-H2964.

185. Takeshita, J., Byun, J., Nhan, T. Q., Pritchard, D. K., Pennathur, S., Schwartz, S. M., Chait, A., and Heinecke, J. W. (2006) Myeloperoxidase generates 5-chlorouracil in human atherosclerotic tissue: a potential pathway for somatic mutagenesis by macrophages, J. Biol. Chem., 281, 3096-3104.

186. Sokolov, A. V., Kostevich, V. A., Vasilyev, V. B., and Panasenko, O. M. (2018) Hypohalous acids modified lipoproteins as biomarkers of halogenative stress at cardiovascular diseases, in Molecular, Membrane and Cellular Basis of Biosystem Functioning (Volotovsky, I. D., ed.) Izdvo BGU, Minsk, p. 171.

187. Sokolov, A. V., Kostevich, V. A., Gorbunov, N. V., Grigorieva, D. V., Gorudko, I. V., Vasilyev, V. B., and Panasenko, O. M. (2018) A link between active myeloperoxidase and chlorinated ceruloplasmin in blood plasma of patients with cardiovascular diseases, Med. Immunol. (Russia), 20, 699-710.

188. Liu, L., Wang, Y. X., Zhou, J., Long, F., Sun, H. W., Liu, Y., Chen, Y. Z., and Jiang, C. L. (2005) Rapid nongenomic inhibitory effects of glucocorticoids on human neutrophil degranulation, Inflamm. Res., 54, 37-41.

189. Vlasova, I. I., Arnhold, J., Osipov, A. N., and Panasenko, O. M. (2006) pH-dependent regulation of myeloperoxidase activity, Biochemistry (Moscow), 71, 667-677. 